\title{
Antioxidants in cardiovascular therapy: panacea or false hope?
}

\author{
Katarzyna Goszcz ${ }^{1,2}$, Sherine J. Deakin ${ }^{1}$, Garry G. Duthie ${ }^{3}$, Derek Stewart ${ }^{2,4}$, \\ Stephen J. Leslie ${ }^{1,5}$ and lan L. Megson ${ }^{1 *}$
}

${ }^{1}$ Department of Diabetes and Cardiovascular Science, Centre for Health Science, University of the Highlands and Islands, Inverness, UK, ${ }^{2}$ James Hutton Institute, Dundee, UK, ${ }^{3}$ Rowett Institute of Health and Nutrition, Aberdeen, UK, ${ }^{4}$ School of Life Sciences, Heriot Watt University, Edinburgh, UK, ${ }^{5}$ Cardiology Unit, Raigmore Hospital, Inverness, UK

\section{OPEN ACCESS}

Edited by:

Andrew James Webb,

King's College London, UK

Reviewed by:

Suowen $\mathrm{Xu}$,

University of Rochester, USA

Vikas Kapil,

Queen Mary University London, UK

Charlotte Elizabeth Mills,

King's College London, UK

*Correspondence:

Ian L. Megson,

Department of Diabetes and

Cardiovascular Science, Centre for

Health Science, University of the

Highlands and Islands, Inverness IV2

3JH, UK

ian.megson@uhi.ac.uk

Specialty section:

This article was submitted to

Cardiovascular Therapeutics, a section of the journal Frontiers in Cardiovascular Medicine

Received: 13 April 2015 Accepted: 10 June 2015 Published: 06 July 2015

Citation:

Goszcz K, Deakin SJ, Duthie GG, Stewart D, Leslie SJ and Megson IL (2015) Antioxidants in cardiovascular

therapy: panacea or false hope?

Front. Cardiovasc. Med. 2:29.

doi: 10.3389/fcvm.2015.00029
Oxidative stress is a key feature of the atherothrombotic process involved in the etiology of heart attacks, ischemic strokes, and peripheral arterial disease. It stands to reason that antioxidants represent a credible therapeutic option to prevent disease progression and thereby improve outcome, but despite positive findings from in vitro studies, clinical trials have failed to consistently show benefit. The aim of this review is to re-appraise the concept of antioxidants in the prevention and management of cardiovascular disease. In particular, the review will explore the reasons behind failed antioxidant strategies with vitamin supplements and will evaluate how flavonoids might improve cardiovascular function despite bioavailability that is not sufficiently high to directly influence antioxidant capacity. As well as reaching conclusions relating to those antioxidant strategies that might hold merit, the major myths, limitations, and pitfalls associated with this research field are explored.

Keywords: antioxidants, vitamin C, vitamin E, carotenoids, polyphenols, vascular disease, $\mathrm{N}$-acetylcysteine, allopurinol

\section{Introduction}

Inappropriate oxidation of biomolecules is a hazard associated with all aerobic life. Harmful oxidation is often mediated by reactive oxygen species (ROS) that are generated by a wide range of biological processes, including mitochondrial respiration and both enzymatic and non-enzymatic chemical reactions. The long-standing but simplistic view of ROS is that they are harmful to cells, contributing to the aging process [the so-called free radical theory of aging (1)] and implicit in a wide range of disease processes, including cancer and cardiovascular disease. However, the complexity of the interaction between cells and ROS is evident in the fact that cells can generate ROS deliberately in small amounts to act as signaling molecules (2), deliberately in large amounts to act as part of the immune defense mechanism (3), or inadvertently through the respiratory chain (4) or other metabolic processes. Indeed, the free radical theory of aging is no longer universally accepted on account of the fact that two of the most effective interventions for improving health, caloric restriction and physical activity, induce a counter-intuitive induction of mitochondria-derived ROS (5). How then are the ROS generated under these conditions beneficial? The answer lies in the adaptive response that the cells mount to counter the potential for deleterious effects. In particular, there is strong evidence that repeated low-level bouts of oxidative stress up-regulate endogenous antioxidant defense mechanisms, which might drive paradoxical improved health and longevity (6). To label oxidative stress as universally harmful is, therefore, inaccurate; its propensity toward harm is a function of the site and amount of ROS generation and can be ameliorated or entirely reversed by the compensatory adaptive response. 
Antioxidants are substances that "neutralize" ROS before they are able to react with cellular components and alter their structure or function. According to the free radical theory of aging, antioxidants were considered to be universally protective and beneficial; hence, the familiar manufacturers' claims that foods, drinks, and supplements are "high in antioxidants," with the subliminal inference that they must therefore be "good for you." This generalization is misleading for a number of reasons. First, it implies that all antioxidants are the same; the truth is that the term "antioxidant" applies to a very wide variety of chemical entities that share only the capability of chemical reduction (donation of electrons). Importantly, dietary antioxidants span the chemical spectrum; some are highly lipophilic with long alkyl chains (e.g., vitamin E, carotenoids), while others are highly water-soluble (e.g., vitamin C). In addition, the size and complexity of antioxidants varies from the small and simple (e.g., salicylates; RMM 170) to very complex polyphenolic agents, like tannic acid (RMM $\sim 1700)$. This chemical diversity impacts heavily on bioavailability, metabolism, and cellular distribution of any given antioxidant; lipophilicity will predispose to accumulation in cell membranes and circulating lipoproteins, while water-soluble agents are unlikely to penetrate cell membranes without the aid of transporters. Bioavailability is a highly complex issue that depends on resistance to digestion and metabolic conversion by the gut microbiome $(7,8)$, absorption, metabolism, and clearance. Finally, antioxidants are, by definition, rapidly oxidized; while this is less of an issue for those that can be stored in solid form, it is an important consideration upon dissolution and in oils. Oxidation before or during ingestion might not only render an antioxidant inert but could also actively promote oxidative stress, depending on the nature of the product formed.

There is a wealth of literature relating to the benefits or otherwise of antioxidants in cardiovascular disease, but there is no consensus as to the relative merits of this therapeutic approach, partly on account of the heterogeneity among study populations, coupled with the wide variety of different antioxidant approaches undertaken - from dietary interventions (e.g., fruit and vegetables, foods, snacks, drinks, and multivitamins) to specific antioxidants (e.g., vitamin C, vitamin E, quercetin, resveratrol, epicatechin, $N$-acetylcysteine, allopurinol). While several clinical studies have suggested that diets rich in fruit and vegetables protect against cardiovascular disease (9-13), the evidence supporting the notion of protective effects of particular diets, or components therein, is both complex and contradictory. In this review, we aim to critically assess the preclinical and clinical evidence with a view to making some sense of the conflicting data. In particular, we will focus on the role of oxidative stress in atherogenic disease progression, prior to evaluating the evidence surrounding antioxidants in foods, drinks, and supplements.

\section{Oxidative Stress, Antioxidants, and Cardiovascular Disease}

Oxidative stress - an imbalance between pro-oxidants and antioxidants, in favor of the former - is an important contributory factor to the atherogenic process (14). Many conditions linked to cardiovascular disease are associated with excessive pro-oxidant
TABLE 1 | Pro-oxidant substances.

\begin{tabular}{|c|c|c|c|}
\hline \multicolumn{2}{|c|}{ Free radicals } & \multicolumn{2}{|c|}{ Non-radicals } \\
\hline $\begin{array}{l}\text { Reactive } \\
\text { oxygen } \\
\text { species }\end{array}$ & $\begin{array}{l}\text { Reactive } \\
\text { nitrogen } \\
\text { species }\end{array}$ & $\begin{array}{l}\text { Reactive } \\
\text { oxygen } \\
\text { species }\end{array}$ & $\begin{array}{c}\text { Reactive } \\
\text { nitrogen } \\
\text { species }\end{array}$ \\
\hline $\begin{array}{l}\text { Superoxide } \\
\text { Hydroxyl } \\
\text { Hydroperoxyl } \\
\text { Peroxyl }\end{array}$ & $\begin{array}{l}\text { Nitric oxide } \\
\text { Nitrogen dioxide }\end{array}$ & Hydrogen peroxide & $\begin{array}{l}\text { Peroxynitrite } \\
\text { Nitrite }\end{array}$ \\
\hline
\end{tabular}

production and/or depression of endogenous antioxidant status; examples include diabetes, hyperlipidemia, hypertension, and obesity (15-19). In addition, a range of environmental factors [e.g., tobacco smoke $(20-22)$, pollution $(23,24)$ ] is known to contribute to oxidative stress and to promote cardiovascular disease. Pro-oxidant substances can be described as either free radical species or non-radical species that mediate peroxidation; the two major sub-groups are ROS and reactive nitrogen species (RNS; Table 1).

Antioxidants are either endogenous, derived from diet, or in the form of therapies. Endogenous antioxidants include superoxide dismutase (SOD), catalase, glutathione (GSH), GSH peroxidase $(\mathrm{GPx})$, thioreductase, and uric acid. Dietary sources include vitamins $\mathrm{A}, \mathrm{C}$, and $\mathrm{E}$, as well as polyphenolic compounds and minerals (25), while $N$-acetylcysteine and allopurinol are therapeutic agents under investigation for antioxidant effects.

Coronary artery disease, stroke, peripheral vascular disease, hypertension, and heart failure are examples of cardiovascular diseases that are considered to be valid targets for antioxidant therapy. Atherosclerosis is the pathological process that underlies coronary artery disease, leading to myocardial infarction, as well as other vascular disease leading stroke and peripheral vascular disease. Given the importance of atherosclerosis in cardiovascular disease, it will form the focus of this review, although some of the studies described transgress the boundaries into related conditions, such as hypertension and heart failure.

\section{Atherosclerosis}

Dysfunction of the endothelial cells that line all blood vessels is a key early event in the development of atherogenesis (26). The endothelium is an active monolayer of cells with a wide variety of key roles, including control of vascular tone, smooth muscle cell proliferation, platelet aggregation, inflammation, and maintenance of vessel wall permeability $(14,26,27)$. Endothelial cells are particularly susceptible to oxidative stress, not only through ROS-mediated cell death but also because the bioavailability of the normally protective mediator, nitric oxide (NO), is compromised through its very rapid reaction with superoxide anion (28). As well as eliminating the protective effects of $\mathrm{NO}$, this reaction generates peroxynitrite $\left(\mathrm{ONOO}^{-}\right)$, a highly cytotoxic RNS, which can also mediate peroxidation of arachidonic acid derivatives to form isoprostanes and malondialdehyde (MDA), lipoproteins to form oxidized LDL, and n-6 polyunsaturated acids to form 4-hydroxynonenal (29-32). 
Smoking (33), diesel particulate matter (23), diabetes (34), hyperlipidemia (35), and hypertension (36) are risk factors for atherosclerosis that are associated with oxidative stress. Disease progression is often considered to be an inflammatory process, which ultimately results in lipid deposition in the intima of the blood vessel wall $(27,37,38)$. Atherosclerosis is a continuous process, but is often categorized into three stages: fatty streak formation, fibrous plaque development, and establishment of a complicated plaque. The fatty streak is instigated by damage to the endothelium, resulting in expression of cellular adhesion molecules, such as vascular adhesion molecule-1 (VCAM1), which ultimately leads to recruitment of monocytes into the sub-endothelial space. Monocytes are activated by cytokines to differentiate into macrophages (Figure 1). Accumulation of macrophages in the vessel wall does not necessarily constitute a problem because, ordinarily, inflammation is rapidly resolved. However, a crucial step in progression of this inflammatory event into a chronic disease process hinges on oxidative stress because LDL, which usually diffuses freely across the endothelium, readily undergoes peroxidation to ox-LDL, triggering recognition by scavenger receptors on activated macrophages now resident in the vessel wall. Phagocytosis of ox-LDL by macrophages traps the lipoprotein in the intima and the now bloated macrophages take on a new identity - "foam cells" (39) (Figure 1). The fibrous plaque is characterized by a stable cap of proliferated smooth muscle cells and fibroblasts, which secrete collagen and other connective tissue, enveloping a cholesterol-rich, lipid, and collagen core. The final stage of plaque development, the complicated plaque, results in an unstable lesion characterized by inflammation, necrosis, ulceration, hemorrhage, and thrombus, which can ultimately be responsible for the occlusion of the blood vessel, with clinical consequences of myocardial infarction, stroke, or peripheral ischemia, depending on the location (40).

Oxidative stress has a clear role in the onset and the progression of atherosclerosis, impinging on a number of points in the disease process (Figure 1). As such, it is an attractive target for antioxidant therapy, but the success or otherwise of proposed interventions will rely on the ability to deliver sufficient amounts of the appropriate antioxidant to the right target, which is not a trivial issue to resolve.

\section{Antioxidant Defense}

Cells synthesize and accumulate a wide variety of powerful antioxidants, including vitamins (A, C, and E), and enzymes (e.g., SOD, catalase, GPx, and thioredoxin reductase). Among other non-enzymatic antioxidants available for cells are $\operatorname{GSH}(41,42)$, and the diet-derived free radical scavengers, carotenoids, and polyphenols, assuming that they accumulate in sufficiently high concentrations to be effective in this mode.

\section{Primary Defense Mechanisms}

In a state of oxidative stress, antioxidants help to mitigate against damage by removing potential oxidants or transforming them into less reactive compounds. The function of the so-called primary defense mechanism is to prevent the oxidative damage directly by intercepting free radicals before they can damage intracellular targets. The endogenous enzymes are central in primary defense

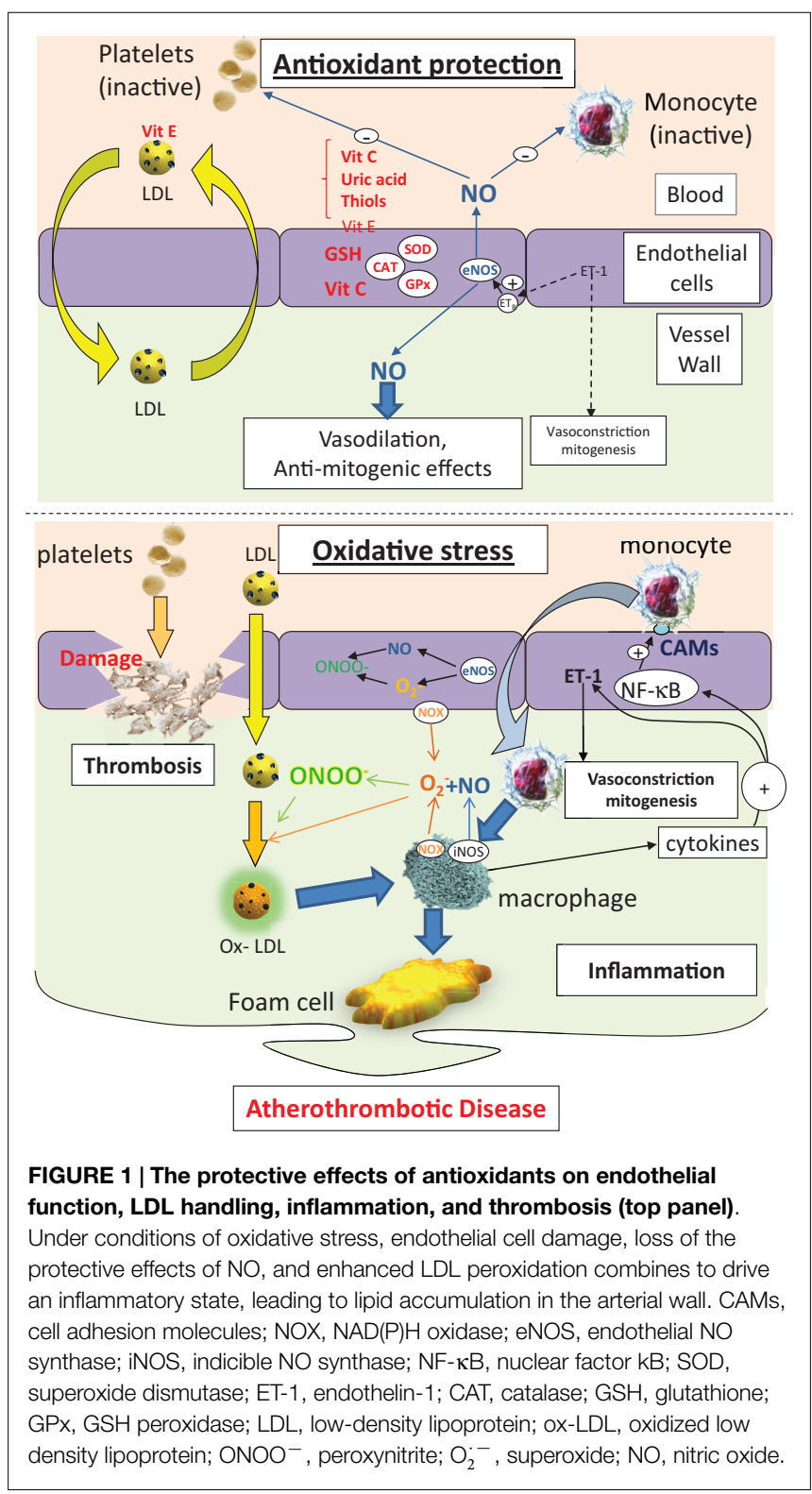

$(43,44)$. SOD is responsible for converting superoxide radical to hydrogen peroxide as follows:

$$
\mathrm{O}_{2}^{\cdot-}+\mathrm{O}_{2}^{\cdot-}+2 \mathrm{H}^{+} \frac{\mathrm{SOD}}{\rightarrow} \mathrm{H}_{2} \mathrm{O}_{2}+\mathrm{O}_{2}
$$

Primary defense against $\mathrm{H}_{2} \mathrm{O}_{2}$ is mediated by the enzymes catalase and GPx, which transform $\mathrm{H}_{2} \mathrm{O}_{2}$ into water and molecular oxygen:

$$
2 \mathrm{H}_{2} \mathrm{O}_{2} \frac{\text { catalase }}{\rightarrow} 2 \mathrm{H}_{2} \mathrm{O}+\mathrm{O}_{2}
$$

The GSH system is an important cellular defense mechanism against free radicals. GSH not only acts as a direct ROS scavenger but also plays a fundamental role in the regulation of the intracellular redox state. The system consists of GSH, GPx, and GSH reductase. GPx is an enzyme that catalyzes the reduction of $\mathrm{H}_{2} \mathrm{O}_{2}$ to water utilizing GSH as a co-substrate:

$$
\mathrm{H}_{2} \mathrm{O}_{2}+2 \mathrm{GSH} \frac{\mathrm{GPx}}{\rightarrow} \mathrm{GSSG}+2 \mathrm{H}_{2} \mathrm{O}
$$


Glutathione disulfide (GSSG) is then reduced back to GSH by GSH reductase:

$$
\mathrm{GSSG}+\mathrm{NADPH}+\mathrm{H}^{+} \rightarrow 2 \mathrm{GSH}+\mathrm{NADP}^{+} .
$$

The ability of cells to regenerate GSH (through the reduction of GSSG or by de novo synthesis of GSH) reflects efficiency of the cell in managing oxidative stress (44).

\section{Secondary Defense Mechanisms}

Secondary antioxidant defense mechanisms - also known as chain-breaking defenses - trap harmful radicals before they can inflict damage. Many small molecules widely distributed in biological systems can scavenge free radicals as a part of the secondary defense system, including vitamin $\mathrm{C}$, uric acid, and free and protein-incorporated cysteine (e.g., Cys 34 in albumin).

Lipid soluble antioxidants, such as vitamin E, are present in cell membranes and protect against lipid peroxidation. Vitamin E converts oxygen-centered free radicals to less reactive form by donating a hydrogen ion. Nuclear enzymes involved in DNA repair can be considered to be secondary defense systems against oxidative injury caused by oxygen free radicals. Many GSH transferases that express peroxidase activity are considered to also protect against lipid peroxidation (43).

\section{Antioxidant Therapies}

In an effort to make some sense of the range of outcomes achieved with antioxidants and to take into consideration the concept that each antioxidant has different merits and should be considered as a separate entity, we will examine each of the most studied antioxidants individually. However, it is important to highlight the findings of large multivitamin supplement clinical trials to frame the findings for individual antioxidants (vitamin, mineral, or other) to follow. For clarity, we have not included supplements and drugs that have well-characterized primary actions that might be complemented by antioxidant activity. For example, antioxidant activity has been described as one of several pleiotropic effects attributable to statins (45-47), but their principle activity is through inhibition of hydroxy-3-methylglutaryl-CoA (HMG-CoA) reductase. Similarly, polyunsaturated fatty acids [e.g., omega-3 fatty acids, docosahexanoic acid (DHA) and eicosapentaenoic acid (EPA)] might have antioxidant effects (48-51), but they also have a major impact on the balance between pro- and anti-inflammatory eicosanoids (52-55). In these cases, more than others, it is difficult to attribute any effects seen in clinical studies to antioxidant activity as opposed to alternative actions, but it is nevertheless acknowledged that they have the potential for antioxidant effects.

\section{Multivitamin Clinical Trials}

The blanket approach of daily multivitamin therapy is appealing because it negates the need to identify the active ingredient simply deliver all the essential vitamins at the agreed recommended daily allowance to ensure that none are deficient. Another potential benefit of a multivitamin approach is that there might be synergistic effects of the vitamins and minerals included in the supplement. The risk, however, is that individuals might view multivitamin supplements as a substitute for a healthy fruit and vegetable-rich diet, leading to deprivation of other beneficial micronutrients and health-enhancing components (e.g., fiber), which might hold just as much, if not more, promise than the vitamins themselves.

A range of case-control studies have reported on the potential benefits of multivitamins in cardiovascular disease. While some show a reduction in cardiovascular risk associated with multivitamin use $(56,57)$, others do not (58-60). Perhaps most tellingly, a large (14,641 male participants) randomized placebo-controlled trial among US physicians (PHS II) failed to identify any difference in cardiovascular outcomes between the multivitamin group and the placebo group (61). A limitation of this study is that the study group (US physicians) is highly educated and likely to be well-nourished, with a balanced diet; vitamin supplements might be superfluous in such a group. Nevertheless, in response to these and other trials, the US Preventative Services Task Force statement regarding multivitamins for prevention of cardiovascular disease and cancer reads "no recommendation" on account of insufficient evidence to determine the balance of benefits and harm (62). Furthermore, a comprehensive Cochrane review (63) of the impact of antioxidant supplements (administered singly or in various combinations) on healthy individuals (26 trials), or in people with one or more of a range of diseases (52 trials), including cardiovascular disease (10 trials), found no overall reduction in all-cause mortality, irrespective of the combination of antioxidants used. Indeed, the findings of the review indicate that some antioxidants ( $\beta$-carotene, vitamin $\mathrm{A}$, and vitamin $\mathrm{E}$ ) have the potential to increase mortality, either singly or in combination with other antioxidant supplements.

These findings and the conclusions drawn provide a backdrop for all of the data relating to individual vitamins and minerals that have been advocated in protection against cardiovascular disease, the essence of which is covered in the sections to follow.

\section{Vitamin C \\ Biochemistry}

Vitamin C (ascorbate or ascorbic acid) is a water-soluble vitamin found in high concentrations in fruit and vegetables, particularly citrus fruit, kiwi, cantaloupe, mango, strawberries, and peppers (64). Dietary ascorbate is essential for humans because we lack the enzyme, L-gulono- $\gamma$-lactone oxidase, required to synthesize it (65). The recommended daily allowance for ascorbate varies from country to country (40-90 mg/day) derived from knowledge about both the minimum requirement to prevent scurvy - the debilitating disease that is caused by chronic vitamin $\mathrm{C}$ deficiency (66) - and the threshold plasma concentration that drives excretion. However, it has long been recognized that vitamin $\mathrm{C}$ is an antioxidant and that its consumption may be beneficial in reducing the impact of oxidative stress in a range of disease processes (64).

Vitamin $\mathrm{C}$ is a strong reducing agent that is reported to provide cytoprotection by scavenging ROS, and hence, protecting DNA, protein, and lipids against peroxidation (64). The powerful ability of vitamin $\mathrm{C}$ to eliminate ROS results in its oxidation to inactive dehydroascorbate; hence, its notoriety as a "sacrificial" 


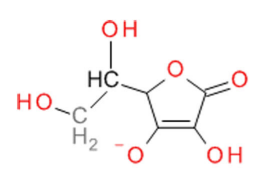

Ascorbate

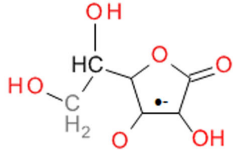

Ascorbyl Radical

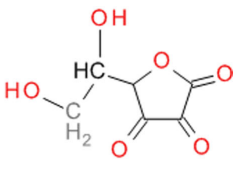

Dehydroascorbate
FIGURE 2 | Vitamin C (ascorbate) and its oxidation products

antioxidant. However, it is important to recognize that vitamin $\mathrm{C}$ is also capable of recycling other endogenous antioxidants, including vitamin E (67). The free radical scavenging ability of vitamin $\mathrm{C}$ is attributed to donation of two electrons from a double bond between the second and third carbons in the ring (Figure 2). Among the ROS scavenged are superoxide, hydroxyl radicals, peroxyl radicals, NO, and many non-radicals, such as hydrochlorous acid and nitrosating agents (64).

The importance of vitamin $\mathrm{C}$ in cellular function is highlighted by its very high intracellular concentration $(>1 \mathrm{mM})(68)$, which is considerably greater than that in the plasma (typically 30-80 $\mu \mathrm{M})$. There are specific transport systems for uptake and accumulation of vitamin $C$ in cells: sodium-dependent vitamin $\mathrm{C}$ transporters (SDVC-1 and SDVC-2) transport the reduced form of the vitamin, while the hexone transporters, GLUT-1 and GLUT3, transport dehydroascorbic acid (69-71).

On a cautionary note, however, despite the many beneficial properties of vitamin $\mathrm{C}$, in the presence of metal ions, it can be prooxidant by catalyzing the reduction of $\mathrm{Fe}^{3+}$ to $\mathrm{Fe}^{2+}$ (66), which can then take part in Fenton chemistry, producing highly reactive hydroxyl radicals, resulting in oxidative damage to proteins, lipids, and DNA (72):

$$
\begin{aligned}
& \mathrm{Fe}^{3+}+{ }^{\bullet} \mathrm{O}_{2-} \longrightarrow \mathrm{Fe}^{2+}+\mathrm{O}_{2} \\
& \mathrm{Fe}^{2+}+\mathrm{H}_{2} \mathrm{O}_{2} \longrightarrow \mathrm{Fe}^{3+}+\mathrm{OH}^{-}+{ }^{\bullet} \mathrm{OH}
\end{aligned}
$$

It is also important to acknowledge that, by definition, vitamins are only required in small quantities. Indeed, absorption of vitamin $\mathrm{C}$ occurs at variable rates, depending on the intake ( $\sim 100 \%$ with low intake and as low as $\sim 30 \%$ with high intake) (68). Similarly, there is relatively tight regulation of the plasma concentration on account of a renal re-absorption threshold for clearance at $\sim 80 \mu \mathrm{M}$ (68). In addition, vitamin $\mathrm{C}$ is readily oxidized by the endogenous enzyme, L-ascorbate oxidase; taken together, these biological regulators ensure a degree of homeostasis for plasma vitamin $\mathrm{C}$ at concentrations that rarely drift below 30 or above $80 \mu \mathrm{M}$. This is important because increased ingestion in an individual with a relatively healthy diet will have only a transient impact on plasma concentration and quite possibly none at all. Indeed, the recommended daily allowance has been reached with consideration of the pharmacokinetics of vitamin C.

\section{In Vitro and In Vivo Animal Studies}

The inflammatory response seen in atherosclerosis can be inhibited by vitamin $\mathrm{C}$ by preventing leukocyte aggregation and adhesion to the endothelium, induced by cigarette smoke in vitro (73). Vitamin $\mathrm{C}$ also has the potential to prevent lipid peroxidation, central to atherosclerosis, by inhibiting oxidation of LDL and subsequent uptake of ox-LDL $(64,74)$.
Mice lacking L-gulono- $\gamma$-lactone oxidase $\left(\mathrm{Gulo}^{-/-}\right)$, the enzyme essential for vitamin $\mathrm{C}$ synthesis, show extensive vascular damage, including elastic lamina disruption, smooth muscle cell proliferation, and desquamation of endothelial cells, when vitamin $\mathrm{C}$ is withdrawn from their diets, highlighting the essential nature of vitamin $C$ in vascular development and function (75). In the Apo- $\mathrm{E}^{-1-} / \mathrm{Gulo}^{-1-}$ atherosclerotic mouse model, plaque development was found to be unaffected by vitamin $\mathrm{C}$ deficiency, but reduced collagen deposition in plaques suggested the potential for increased risk of rupture in this in vivo animal study (76).

\section{Clinical Studies and Trials}

The fact that the majority of animal species synthesize vitamin $\mathrm{C}$ makes animal studies difficult. A number of small-scale clinical studies have investigated the impact of vitamin $C$ on several factors associated with vascular health. The British Regional Heart Study found an inverse association between plasma vitamin $\mathrm{C}$ concentration and markers of inflammation and endothelial dysfunction in men with no history of cardiovascular disease or diabetes (77). In addition, acute administration of vitamin C (3 g) improved endothelium-dependent vasodilation in the epicardial coronary artery in patients with hypertension (78). Endothelial dysfunction has been identified as the major target for vitamin C-mediated effects. For example, in patients with coronary artery disease or hyperglycemia-induced impairment of vasodilation, $\mathrm{NO}$-mediated vasodilation is restored with either oral $(6 \mathrm{~g}$ over 2 days) or intra-arterial infusion $(24 \mathrm{mg} / \mathrm{min}$ for $10 \mathrm{~min}$ ) of vitamin $C(79,80)$. The precise mechanism underlying this effect is not yet clear, but it has been postulated that, as well as scavenging ROS, vitamin $\mathrm{C}$ might impact on $\mathrm{NO}$ bioavailability through direct stimulation of the enzyme responsible for synthesis of $\mathrm{NO}$ (endothelial NO synthase: eNOS), or enhanced synthesis of an essential cofactor for NOS activity, tetrahydrobiopterin $\left(\mathrm{BH}_{4}\right)(81$, 82). Likewise, oral vitamin $\mathrm{C}$ administration ( $2 \mathrm{~g}$ ) was found to reduce arterial stiffness and platelet aggregation in healthy individuals; the mechanism involved was not established in this study, but improved endothelial function was considered to be a strong possibility (83).

The European prospective investigation into cancer and nutrition (EPIC) Norfolk study found that plasma vitamin C concentration was inversely related to incidence of cardiovascular disease-related mortality, as well as all-cause mortality, in both men and women. The study recruited nearly 20,000 individuals aged 45-79 years and monitored plasma vitamin $C$ and all-cause mortality, with a particular focus on cardiovascular disease and cancer, for $\sim 4$ years. It was determined that by increasing plasma vitamin $\mathrm{C}$ by $20 \mu \mathrm{M}$ through increased intake of fruit and vegetables, cardiovascular disease mortality was reduced by $\sim 20 \%$ (84). By contrast, only the smallest two of seven vitamin $\mathrm{C}$ supplement studies included in a recent meta-analysis (85) have shown any benefit in reducing major cardiovascular events, leading to the conclusion that vitamin $\mathrm{C}$ has no effect on this end point. A large-scale study conducted over 20 years found that diets rich in vitamin $\mathrm{C}$ were associated with a lower incidence of stroke in elderly people ( +65 years), but no significant association was found with coronary heart disease (86). Taken together, these findings infer that vitamin $\mathrm{C}$ might not be the active agent in the 
effect seen in the Norfolk trial, but that the benefits shown by eating sufficient fruit and vegetables to have a significant impact on plasma vitamin $\mathrm{C}$ induce a protective effect through other fruit and vegetable-derived nutrients. The Cochrane review on antioxidant supplements similarly concludes that vitamin $\mathrm{C}$ fails to reduce all-cause mortality (63).

\section{Vitamin E}

Vitamin E is the most comprehensively studied antioxidant in humans, to date, particularly with respect to large-scale clinical trials. The results of these trials have had a major impact on the perception of antioxidants as whole in the cardiovascular arena.

\section{Biochemistry}

The term "Vitamin E" refers to eight lipid soluble, isomeric compounds containing three asymmetric carbon atoms, known as tocopherols and tocotrienols (Figure 3). The major isoforms in human diet are $\alpha$ - and $\gamma$-tocopherol; $\alpha$-tocopherol is the bestresearched as it is the most potent antioxidant of the group (8789). Cooking oils, egg yolk, butter, green leafy vegetables, and some fruits (kiwi fruit, pumpkins, mangoes, papayas, and tomatoes) are rich sources of vitamin E. While vitamin E deficiency can cause serious health problems, it usually occurs in premature babies who have genetic deficiency in tocopherol transport protein or have fat absorption problems - it is rarely due to deficiency in the diet (90).

The tocopherols and tocotrienols are absorbed with fats through a non-specific uptake mechanism in the intestine, from where they are transported to the liver in chylomicrons prior to secretion in very low density lipoproteins (VLDL). VLDL is subject to delipidation and converted to $\mathrm{LDL}$, enriching all lipoproteins with vitamin E. LDL transport is essential for delivering vitamin $\mathrm{E}$ into tissues; unbound vitamin $\mathrm{E}$ is hydrophobic, making it immiscible with the aqueous plasma and cellular compartments (87).

\section{In Vitro and In Vivo Animal Studies}

In vitro and in vivo animal experiments have led to the proposal that vitamin $\mathrm{E}$, and $\alpha$-tocopherol, in particular, has protective qualities that might help to prevent cardiovascular disease. In vitro studies have shown that $\alpha$-tocopherol can protect against oxidative stress, inflammation, and endothelial dysfunction, all of which are characteristic of atherosclerotic plaque development. For example, monocyte adhesion to the endothelium can be reduced in the presence of $\alpha$-tocopherol in cultured monocytes (91) and primary human monocytes (92). Vitamin E has also been shown to inhibit expression of adhesion molecules, VCAM-1 and<smiles>Cc1c(C)c2c(c(C)c1O)CCC(CCCCCCCCCCCC(C)C)O2</smiles>

$\alpha$-tocopherol<smiles>Cc1ccc2c(c1C)OC(CCCCCCCCCCCC(C)C)CC2</smiles>

$\beta$-tocopherol<smiles>Cc1c(O)cc2c(c1C)OC(CCCCCCCCCCCC(C)C)CC2</smiles>

y-tocopherd<smiles>Cc1cc(O)cc2c1OC(CCCCCCCCCCC(C)C)CC2</smiles>

$\delta$-tocopherol<smiles>CC(C)=CCC/C(C)=C/CC/C(C)=C/CCC1CCc2c(C)c(O)c(C)c(C)c2O1</smiles>

$\alpha-$-tocotienol<smiles>CC(C)=CCCC(C)=CCCC(C)=CCCC1CCc2c(C)c(O)cc(C)c2O1</smiles>

$\beta$-tocotriend<smiles>CC(C)=CCCC(C)=CCCC(C)=CCCC1CCc2c(C)c(c(C)c(C)c2O)O1</smiles>

$\gamma$-tocotriend<smiles>CC(C)=CCC/C(C)=C/CC/C(C)=C/CC[C@@H]1CCc2cc(O)c(C)c(C)c2O1</smiles>

FIGURE 3 | Structure of tocopherols and tocotrienols. 
ICAM-1, on cultured endothelial cells stimulated by ox-LDL (93). Vascular smooth muscle cell proliferation can also be inhibited by $\alpha$-tocopherol via inhibition of protein kinase C activity (94).

The effects of vitamin $\mathrm{E} / \alpha$-tocopherol in in vivo animal models are inconclusive. For example, $\alpha$-tocopherol can significantly lower circulating $\mathrm{C}$ reactive protein (CRP), an inflammatory marker that is associated with atherosclerosis (95) and, importantly from an antioxidant perspective, vitamin E supplementation can protect LDL from peroxidation, which may slow atherosclerotic plaque development (96). Lipid peroxidation can be prevented by $\alpha$-tocopherol, through scavenging of ROS, preventing the early stages of atherosclerosis, and limiting the damage caused during ischemia reperfusion, where excessive ROS are produced $(97,98)$. In addition, vitamin E supplementation has been shown to reduce intravascular fatty deposits and macrophage activation in a mouse model of diabetes in which the animals are ordinarily prone to developing atherosclerosis (99). By contrast, however, vitamin E supplementation failed to reduce atherosclerotic lesion size or levels of 8 -iso-prostaglandin $\mathrm{F}_{2 \alpha}$, a marker of oxidative stress, in obese hyperlipidaemic mice (100).

\section{Clinical Studies and Trials}

Vitamin E has been the subject of two large clinical trials: the Cambridge heart antioxidant study (CHAOS) and the heart outcomes prevention evaluation study (HOPE). The results from CHAOS showed some promise in that, while $\alpha$-tocopherol supplementation failed to have an impact on cardiovascular mortality rates, it succeeded in reducing the incidence of non-fatal myocardial infarction in patients with coronary artery disease (101). Results from the HOPE trial, however, were disappointing, because vitamin E supplementation was found to have no effect on cardiovascular outcomes in patients at high risk of cardiovascular events or in patients with diabetes $(102,103)$. It is difficult to speculate on the reasons for this difference because both studies used patients with similar disease profiles, although the HOPE trial measured many more outcomes than CHAOS. The CHAOS trial only recruited patients with angiographically proven coronary artery atherosclerosis, whereas the HOPE trial recruited those at high risk of cardiovascular disease. Vitamin E was administered in the same way in both trials, but initially in CHAOS, a high dose (800 IU) was administered to the first group of patients recruited. Irrespective of the minor differences between individual studies, the antioxidant Cochrane review found that vitamin $\mathrm{E}$ supplements have the potential to significantly increase all-cause mortality (63).

Despite the disappointing outcomes of these large-scale trials, there is still a broad spectrum of in vitro and in vivo data that support the possibility that vitamin E may exert cardioprotective properties. For example, dietary supplementation with vitamin $\mathrm{E}$ has been shown to inhibit platelet adhesion ex vivo, suggesting a potential benefit in preventing thrombus formation (104). In any event, the results of the HOPE trial dealt a massive blow to vitamin $\mathrm{E}$ as a beneficial antioxidant in cardiovascular disease and led to a widespread sense that the whole concept of antioxidant therapy might be flawed. While the former conclusion might hold some truth, the latter perception is almost certainly unwarranted. The current recommendation from the US preventative task force is that vitamin E supplementation is not recommended in primary prevention of cardiovascular disease (62).

\section{Vitamin A and the Carotenoids Biochemistry}

The carotenoids are a group of lipid soluble, vibrantly colored pigments (yellow, orange, and red) found extensively in fruit and vegetables (Table 2). Retinol (vitamin A) can be synthesized from $\beta$-carotene in the gut, both before and after absorption [Ref. (105) for detailed review]. Lycopene, the precursor for $\beta$-carotene and many other carotenoids, is probably the most studied of this group. It is a potent singlet oxygen scavenger that is twice as effective in this capacity as $\beta$-carotene and 10 times more effective than $\alpha$-tocopherol (106). The remarkable free radical scavenging activity of lycopene has been attributed to its highly unsaturated chemical identity, although it does not vary greatly from other carotenoids in this regard. The structures of the important carotenoids are illustrated in Figure 4.

While lycopene's antioxidant activity might be higher than that of vitamin $\mathrm{E}$ and other diet-derived antioxidants, the limitation to in vivo antioxidant effects revolve around its bioavailability (plasma concentrations typically $<1 \mu \mathrm{M}$ in free living individuals

\section{TABLE 2 | Dietary sources of carotenoids}

\begin{tabular}{ll}
\hline Carotenoid & Dietary source \\
\hline$\beta$-carotene & $\begin{array}{l}\text { Apricot, carrot, spinach, cantaloupe, broccoli, } \\
\text { green beet, tomato }\end{array}$ \\
Lycopene & Tomato, guava, watermelon, pink grapefruit \\
$\alpha$-carotene & Carrot \\
Lutein and zeaxanthin & Spinach, green beet, broccoli, green peas \\
$\beta$-crytoxanthin & Tangerine, papaya
\end{tabular}<smiles>CC(=O)C1(C)CCCC(C)=C1C1(C)CCCC(C)=C1C=CC(C)=CC=CC(C)=CC=CC=C(C)C=CC=C(C)C=CC=C(C)C(C)=CC=CC(C)=CC=CC(C)=CC=CC=C(C)C=CC=C(C)C=CC=C(C)CCC=C(C)C</smiles>

FIGURE 4 | Structure of five major carotenoids in human diet. 
in a placebo-controlled $\beta$-carotene trial) (107). However, the situation is more complex than simply considering raw plasma concentration because lycopene associates with LDL in the plasma, where the local concentration in these lipid-rich moieties will be considerably higher. In addition, the lipid solubility of lycopene ensures that it accumulates in fat-rich organs and tissues (e.g., liver, prostate, testes) (108), where it might reach sufficient concentrations to have a genuine impact on antioxidant capacity. As with other diet-derived components, it is also crucial to consider the effect of cooking and oxidation prior to ingestion, as well as metabolism on the eventual metabolites available in the appropriate compartment to influence biological processes. The impact of cooking is not necessarily detrimental to antioxidant capacity, studies involving thermal processing of tomatoes indicated that heating reduced vitamin $\mathrm{C}$ content, but caused a concomitant increase in bioavailable lycopene, possibly due to release from the matrix of the fruit, and a net increase in antioxidant capacity (109).

\section{In Vitro Studies}

Evidence surrounding carotenoids from in vitro studies is conflicting. For example, $\beta$-carotene, lycopene, and lutein all prevent $\mathrm{Cu}^{2+}$-mediated LDL peroxidation (110). However, a similar study using endothelial cells to induce lipid peroxidation found no benefit from $\beta$-carotene or lycopene enrichment of LDL (111). Both of these studies used similar concentrations of carotenoids; therefore, it is most likely that different results stem from using different models to induce oxidative stress.

In vitro studies indicate that $\beta$-carotene and lycopene are capable of reducing plasma cholesterol levels through inhibition of HMG-CoA reductase, the rate-limiting enzyme involved in cholesterol synthesis. HMG-CoA reductase is the target of the highly successful group of drugs known as statins (e.g., simvastatin, fluvastatin) and therefore constitutes a valid target for plantderived agents. Both $\beta$-carotene and lycopene $(10 \mu \mathrm{M})$ reduced HMG-CoA activity to a similar extent as fluvastatin $(10 \mu \mathrm{g} / \mathrm{ml})$, suggesting a potential therapeutic application for carotenoids. In addition to this, macrophage LDL receptor activity was increased in the presence of these carotenoids, reducing circulating LDL, suggesting a possible a protective role in the cardiovascular system $(112,113)$. By contrast, however, it has been demonstrated in cardiac myocytes and endothelial cells that retinoic acid (the active metabolite of retinol) has been shown to reduce activity of inducible NOS (iNOS), which is usually active during inflammation, producing cytotoxic levels of NO in both cardiac myocytes and endothelial cells (114).

\section{Clinical Studies and Trials}

Many clinical studies have suggested that carotenoids have cardioprotective properties. The Physicians Health Study found that coronary artery disease was less prevalent in men who ate vegetables rich in carotenoids (115). Moreover, recent studies, such as the coronary artery risk development in young adults (CARDIA) and the young adult longitudinal trends in antioxidants (YALTA) studies, have found that high-plasma carotenoid concentrations are associated with reduced inflammation, oxidative stress, and endothelial dysfunction, three important characteristics of atherosclerosis (116), while the Bruneck study found a lower incidence of atherosclerosis in individuals with higher plasma levels of $\beta$-carotene and $\alpha$-carotene (117). Reduction in markers of endothelial dysfunction, such as soluble intercellular adhesion molecule (sICAM-1), and inflammation (CRP) are associated with elevated plasma concentrations of carotenoids resulting from high intake of fruit and vegetables rich in carotenoids (118). By contrast, however, the $\beta$-carotene and retinol efficacy trial (CARET) found an inverse correlation between supplementation and risk of cardiovascular disease; this is the only trial, to date, which has investigated the impact of retinol supplementation on cardiovascular disease, albeit in combination with $\beta$-carotene (119). The EURAMIC study found a weak association between adipose $\beta$-carotene concentration and risk of $\mathrm{MI}$, but the effect was lost after controlling for a range of confounding factors (120). Findings from a more recent study in 1031 Finnish men, however, found a more convincing correlation between serum $\beta$-carotene and reduction in risk of MI (121). Similarly, LDL oxidation was not reduced by $\beta$-carotene in a study in which vitamin $E$ was found to be beneficial (96). Again, there is perhaps a disparity between findings where $\beta$-carotene is used as a marker of fruit and vegetable ingestion and those involving supplements, which could be interpreted to indicate that $\beta$-carotene is a bystander rather than causal in dietary studies. Indeed, based on these studies, the statement from the US Preventative Task Force is to not recommend $\beta$-carotene for prevention of cardiovascular disease (62). Likewise, the Cochrane review on antioxidant supplements and all-cause mortality found $\beta$-carotene and vitamin A to significantly increase all-cause mortality (63).

There has been considerable recent interest in lycopene - the carotenoid that is found in high concentration in tomatoes. In the EURAMIC study, adipose lycopene concentrations correlated with a reduction in risk of $\mathrm{MI}$ and the effect was retained after correction for confounding factors. The odds ratio was modeled in this study using the contrast between the 10th and 90th percentile for adipose lycopene and was found to be 0.52 (120), suggesting that risk of mortality was substantially reduced in those with high-adipose lycopene. A similar correlation has been reported for serum lycopene and a reduction in risk of MI (121). These promising epidemiological studies have prompted a number of small interventional studies, which have generally shown beneficial effects of lycopene on a range of outcome measures related to cardiovascular disease [see Ref. (122) for review]. In short, the data indicate that diet- or supplement-derived lycopene reduces inflammation and oxidative stress markers in overweight and healthy individuals, improves endothelial function, and reduces platelet activity $(123,124)$. Interestingly, the most recent study (125) found that lycopene only improved endothelial function in a patient group and not a parallel healthy volunteer group, perhaps suggesting a therapeutic rather than preventative role for lycopene. All of these studies are small and require confirmation in larger cohorts, but the findings are positive and the antithrombotic data $(123,124)$ were the basis for a patent and the subsequent commercialization of a tomato extract with European Food Standard Agency approval for therapeutic claims.

Compared to $\beta$-carotene and lycopene, the other carotenoids have received considerably less attention. The Los Angeles Atherosclerosis Study demonstrated that lutein-rich diets were 
inversely related to early atherosclerotic lesion development. Moreover, in vitro and knockout mice findings were also presented showing lutein reduced monocyte chemotaxis in an in vitro atherosclerotic model and atherosclerotic lesion size was reduced in lutein-treated apolipoprotein E (Apo-E) and LDL receptor knockout mice (126). Zeaxanthin and $\beta$-cryptoxanthin have not been as intensely investigated as $\beta$-carotene, lycopene, and lutein (127), although plasma lutein, zeaxanthin, and $\beta$-cryptoxanthin (collectively known as the oxygenated carotenoids) have been shown to be inversely associated with coronary artery disease (128).

Despite encouraging in vitro and in vivo data relating to a range of carotenoids, and an apparent correlation between plasma carotenoid concentration and reduced risk of cardiovascular disease in epidemiological studies, data from carotenoid intervention trials have failed to provide incontrovertible evidence in support of carotenoids in cardiovascular disease. However, the findings have not all been negative and the results relating to lycopene in particular suggest that the less convincing findings for $\beta$-carotene should not be taken as indicative of all carotenoids. Indeed, the ex vivo and in vitro data for tomato extracts have been regarded to be sufficiently strong by the European regulatory body to gain rare approval for therapeutic claims.

\section{Folate and Other B Vitamins \\ Biochemistry}

Dark leafy vegetables, such as spinach, are rich sources of folate (folic acid, vitamin B9) and other B vitamins. Folate and the $B$ vitamins have a crucial role in metabolism of the essential amino acid, methionine, with impacts on both homocysteine and antioxidant GSH (Figure 5).

\section{In Vitro and In Vivo Animal Studies}

Homocysteine is believed to induce endothelial dysfunction because its thiol group is easily oxidized, generating ROS, which reduce bioavailability of $\mathrm{NO}$ by direct oxidative inactivation and depletion of intracellular GSH pools $(129,130)$. In addition, homocysteine has been implicated in increased formation of asymmetric dimethyl-L-arginine, an endogenous inhibitor of NOS (131) and in protein kinase $\mathrm{C}$ activation, leading to the inhibition of eNOS and further reducing NO bioavailability (132). Furthermore, vascular inflammation can be promoted by homocysteine through NF- $\kappa \mathrm{B}$-mediated expression of the proinflammatory cytokines, monocyte chemotactic protein (MCP-1), and IL-8 (129). Hyperhomocysteinemia is therefore recognized to be an independent risk factor for cardiovascular disease (133), at least partly via oxidative stress. Homocysteine-lowering therapy is a potential option in homocysteine-driven cardiovascular dysfunction; B vitamins involved in homocysteine cycling and GSH synthesis (Figure 5) represent potential therapeutic agents in this arena.

Folate has been demonstrated to scavenge hydroxyl and lipid peroxyl radicals in vitro (134). The latter is perhaps surprising, given the water solubility of folic acid but, if true, is likely to contribute to any protective effects in cardiovascular disease. Moreover, folate supplementation in vivo in Apo-E knockout mice (135) has been shown to decrease number of atherosclerotic plaques in these animals, and was also associated with a decrease in LDL peroxidation. Similar results have been reported in a homocysteine-induced rat model of atherosclerosis (136), while a further potential use of folate has been identified in an animal model of abdominal aortic aneurysm (137), whereby folate acts to help reverse uncoupling of eNOS implicated in the etiology of the condition.

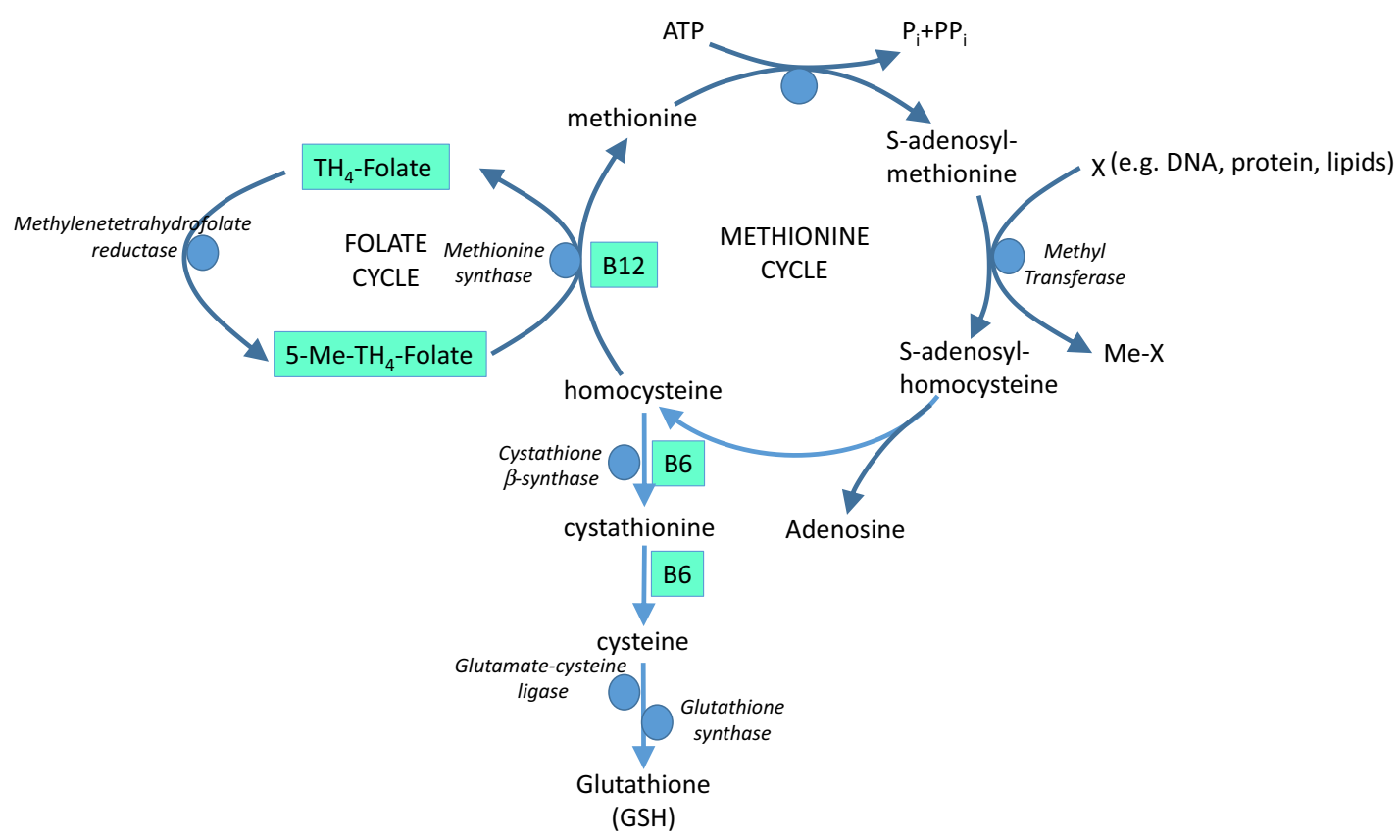

FIGURE 5 | The role of vitamins B9 (folate), B6, and B12 in methionine metabolism and glutathione (GSH) synthesis. 


\section{Clinical Studies and Trials}

Low-circulating levels of folate, vitamin B12, and vitamin B6 are risk factors for stroke, peripheral vascular disease, and coronary artery disease (138). Supplementation of folate, hydroxocobalamin (vitamin B12), and pyridoxine (vitamin B6) reduces serum homocysteine in elderly patients with slightly elevated plasma concentrations (139). A similar study found that folate, hydroxocobalamin, and pyridoxine supplements for 8 weeks reduced serum homocysteine to within the normal range in healthy volunteers and in patients with venous thrombosis (140). Moreover, a similar small-scale supplementation study found a decrease in carotid artery intima-media thickness in high-risk cerebral infarction patients (141). A further positive study showed that lowdose folate supplementation improved endothelial function in patients with cardiovascular disease shortly after receiving a coronary graft. Importantly, the benefits in this study were attributed to improved coupling of endothelial NO synthase through the essential cofactor, tetrahydrobiopterin, rather than by an impact on plasma homocysteine levels (142).

The vitamin intervention for stroke prevention (VISP) randomized controlled trial found no significant effect of folate, hydroxocobalamin, and pyridoxine supplementation in reducing incidence of cerebral infarction, coronary events, or cardiovascular death. Patients with non-disabling cerebral infarction received a high-dose or low-dose folate, hydroxocobalamin, and pyridoxine supplementation for 2 years, after which recurrent cerebral infarction, coronary events, or death was recorded (143).

As with many of the other antioxidant vitamin interventions discussed above, there appears to be a mis-match between the potential of vitamin B supplements shown in vitro and suggested by cohort, prospective, and retrospective clinical studies, and randomized control trials with $\mathrm{B}$ vitamins. In a recent review on the subject (144), a convincing argument is put forward that any beneficial effects of vitamin B (or vitamin E) in intervention studies is masked by the effects of statins, aspirin, and other drugs that patient groups are inevitably receiving. Added to this, we would argue that vitamin therapy is only likely to benefit individuals deficient in the vitamin of choice and could only show benefit in a sub-set of the study populations. The findings of a Cochrane systematic review for vitamin B6, 9, and 12 in cardiovascular disease were that there is no evidence to support the use of these $\mathrm{B}$ vitamins to prevent cardiovascular events (145).

\section{Polyphenolic Compounds Biochemistry}

A polyphenol is defined as a compound that contains two or more phenol groups (146). This large group of compounds is divided into several sub-groups: flavonoids, phenolic acids, stilbenes, and lignans (147) (Figure 6). Polyphenolic compounds are abundant in plants and are readily found in fruit and vegetables (Table 3). In addition, they are important components of herbs and spices and are likely to be critical ingredients in Chinese medicines.

\section{Polyphenols as antioxidants}

The paradigm for the mechanism of action of polyphenols is through direct antioxidant activity, on account of their interaction with ROS, including both radical and non-radical oxygen species, such as $\mathrm{O}_{2}^{--}, \mathrm{H}_{2} \mathrm{O}_{2}, \mathrm{HOCl}, \mathrm{NO}$, as well as those derived from biomolecules, such as LDL, proteins, and oligonucleic acids (DNA, RNA) (149-152). Structural features, such as number and relative position of hydroxyl and catechol groups, determine the antioxidant properties of polyphenols $(150,152,153)$.

Polyphenols can also act as antioxidants by chelating metal ions, such as iron and copper, which are involved in conversion of $\mathrm{O}_{2}^{--}$and $\mathrm{H}_{2} \mathrm{O}_{2}$ into highly aggressive ${ }^{\circ} \mathrm{OH}$ (Fenton chemistry). They can also block the action of some enzymes responsible for generation of superoxide radical, such as xanthine oxidase (XO) and protein kinase $\mathrm{C}$, as well as activating antioxidant enzymes $(150,154)$.

There is an ongoing debate regarding the probability of observed direct antioxidant activities in vivo, since supraphysiological concentrations $(100-400 \mu \mathrm{M})$ of polyphenols were often used in tests determining their antioxidant properties. Low bioavailability $(\sim 1 \mu \mathrm{M})$ of phenolic compounds seriously questions their ability to engage in direct antioxidant potential in the in vivo scenario (152). The emerging concept is that phenolics may induce endogenous antioxidant defense systems through modulation of gene expression, therefore, protecting against oxidative stress in an indirect manner $(154,155)$.

\section{Polyphenols as pro-oxidants}

The pro-oxidant activities of polyphenols are based on their ability to generate ROS. It has been reported that phenolic compounds can oxidize readily in beverages, tissue culture media, and phosphate buffers, especially in the presence of transition metal ions $(156,157)$. Oxidation of polyphenols leads to superoxide radical and $\mathrm{H}_{2} \mathrm{O}_{2}$ production, as well as a complex mixture of semiquinones and quinones, all of which are potentially toxic $(157,158)$. The level of cytotoxicity depends on both the type of polyphenol and the amount of free radicals generated (156).

A variety of polyphenols and polyphenol-containing extracts have been reported to generate ROS, including green tea, black tea, and apple extracts, as well as individual phenolics, such as gallic acid, protocatechuic acid, vanillic acid, ellagic acid, caffeic acid, quercetin, rutin, kaempferol, catechin, epicatechin, delphinidin, and malvidin (158).

The pro-oxidant effects of polyphenols can also be beneficial, since, by imposing a mild degree of oxidative stress, they can induce endogenous antioxidant defense mechanisms. However, the amount of research on the antioxidant potential of polyphenols overshadows the lesser number of studies on the biological implications of their pro-oxidant properties $(154,156)$.

Fruit and vegetable-derived polyphenols have been subject to a great deal of study, providing a substantial body of evidence to support the beneficial effects of these substances on health. Here, we look specifically at the benefits of polyphenols on the cardiovascular system (159), where polyphenols have been found to be associated with a reduction in mortality from cardiovascular disease (160-162), but the mechanisms through which they exert their cardioprotective actions are not yet fully understood (163). The assumption is that the antioxidant properties of polyphenols protect blood vessels against oxidative damage and the associated cardiovascular risk factors $(163,164)$. It has been proposed that polyphenols might protect vascular endothelial cells 


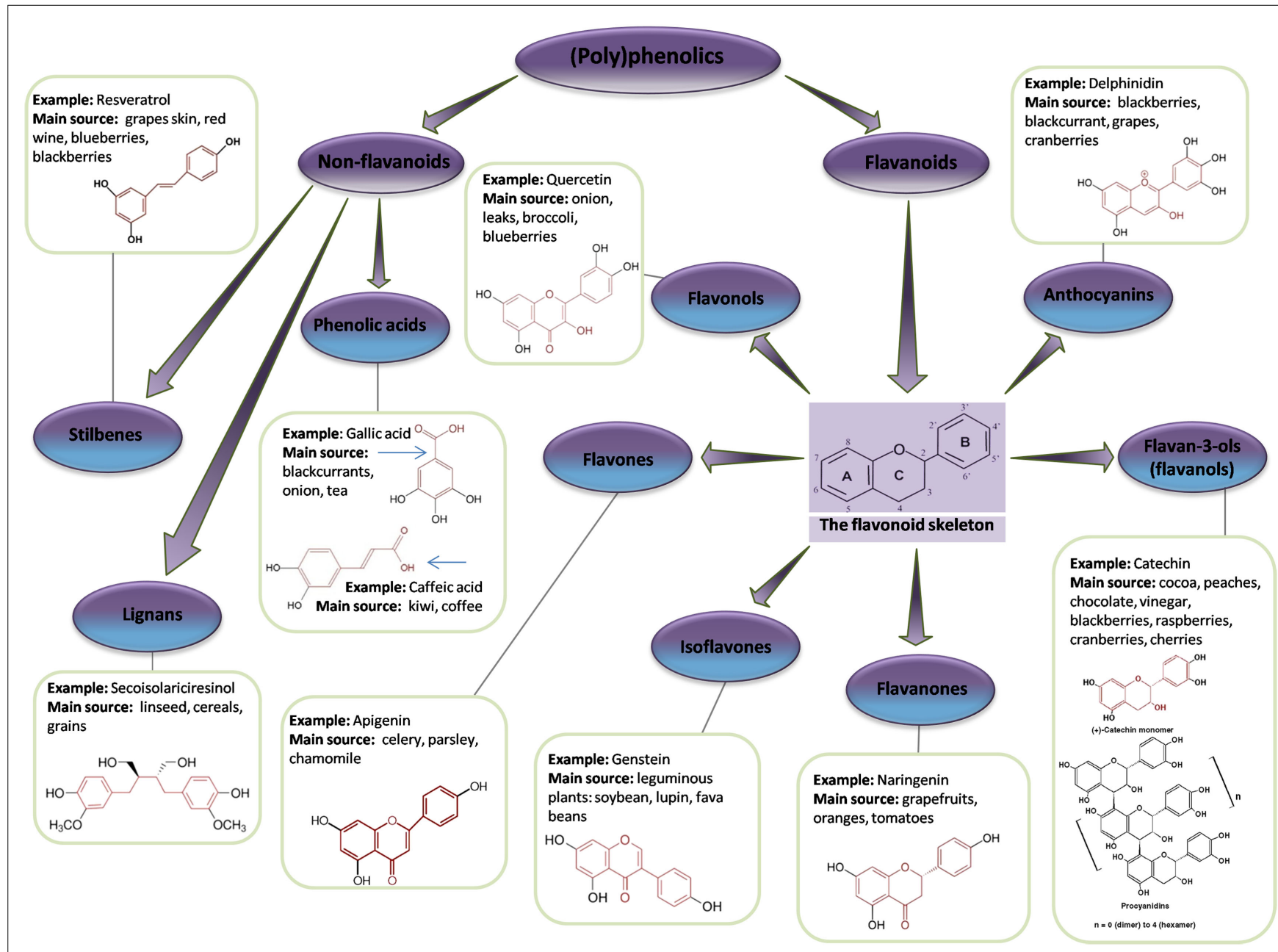

FIGURE 6 | Flavonoid and non-flavonoid phenolic compounds. Schematic showing phenolic compounds, along with typical examples and associated chemical structure (adapted from http://www.frenchglory.com/polyphenol-classification.html).

TABLE 3 | Dietary sources of common (poly)phenolic compounds [adapted from Watson et al. (148)].

\begin{tabular}{|c|c|c|}
\hline Polyphenol class & Examples & Common dietary sources \\
\hline Anthocyanidins & Cyanidin, delphinidin, malvidin, pelargonidin, peonidin, petunidin & $\begin{array}{l}\text { Fruit, red wine, some cereals, aubergines, cabbage, beans, } \\
\text { onions, radishes }\end{array}$ \\
\hline Catechins & Catechin, epicatechin, gallocatechin, epigallocatechin & Tea (black and green), cocoa, chocolate \\
\hline Flavanones & Hesperitin, hesperidin, homoeriodictyol, naringenin, naringin & Citrus fruit, tomatoes, mint \\
\hline Flavones & Apigenin, luteolin, tangeritin, nobiletin, sinensetin & Fruit, vegetables, some cereals, skin of citrus fruit \\
\hline Flavonols & Kaempferol, myricetin, quercitin & Fruit, onions, kale, leeks, broccoli, blueberries, red wine, tea \\
\hline Isoflavones & Daidzein, genistein, glycitein & Soybeans, peanuts, leguminous plants \\
\hline Hydroxybenzoic acids & Gallic acid, $p$-hydroxybenzoic acid, vanillic acid & Tea, wheat, raspberry, blackcurrant, strawberry \\
\hline Hydroxycinnamic acids & Caffeic acid, ferulic acid, $p$-coumaric acid, sinapic acid & Kiwifruit, blueberries, apples, cereals \\
\hline Lignans & Pinoresinol, podophyllotoxin, steganacin & $\begin{array}{l}\text { Flax seed, sesame seeds, some cereals, broccoli, cabbage, } \\
\text { apricots, strawberries }\end{array}$ \\
\hline Stilbenes & Resveratrol & Red wine \\
\hline Tannins & Castalin, pentagalloyl glucose, procyanidins & Tea, berries, wine, cocoa, chocolate \\
\hline
\end{tabular}

against ROS-induced damage, thereby preventing oxidation of LDL and protecting the crucial vasodilator nitric oxide $(\mathrm{NO})$ against oxidation (164-167).

The objection to the direct antioxidant paradigm to explain the beneficial effects of polyphenols in vascular diseases is that polyphenols are characterized by low bioavailability; the concentrations required to induce direct antioxidant activity are infeasible in vivo. Instead, it is becoming increasingly recognized that phenolic compounds can interact with various molecular targets and affect multiple signaling pathways in endothelial 
cells, providing an alternative putative mechanism to define the means by which these agents can induce benefit despite very low concentrations in vivo (150). Prominent among the putative mechanisms triggered by low concentrations of polyphenols is activation of the nuclear factor E2-related factor 2 (Nrf2), antioxidant response element (ARE) pathway (168). Activation of Nrf2 causes it to bind to the enhancer DNA sequence, ARE, which regulates more than 200 genes that code for a wide variety of proteins, including antioxidant and detoxifying enzymes. The key antioxidant enzymes induced are glutamyl-cysteine ligase (GCL the rate-limiting enzyme for GSH synthesis), GPx, thioredoxin, thioredoxin reductase, SOD, and heme oxygenase-1 (HO-1). A wide variety of polyphenols have been identified to be effective activators of this pathway, with the effect of driving a broad spectrum antioxidant response [for review, see Ref. (169)]. In addition, phenolic compounds impact on the cardiovascular system by improving endothelial function, inhibiting angiogenesis, cell migration, and proliferation of blood vessels, and reducing platelet aggregation and hypertension $(164,166,170)$. Plant polyphenols may stimulate the production of major vasodilatory factors [NO, endothelium-derived hyperpolarizing factor (EDHF) and prostacyclin] and inhibit the synthesis of vasoconstrictor endothelin-1 in endothelial cells (171). Moreover, phenolic compounds inhibit the expression of two major pro-angiogenic factors, vascular endothelial growth factor (VEGF), and matrix metalloproteinase2 (MMP-2) in smooth muscle cells (172).

In endothelial cells, one of the mechanisms that drives the effects described above involves $\mathrm{Ca}^{2+}$-mediated activation of the phosphoinositide 3 (PI3)-kinase/Akt pathway, leading to rapid enhanced expression and stimulation of eNOS, as well as formation of EDHF. In smooth muscle cells, polyphenols have been shown to induce both redox-sensitive inhibition of the p38 mitogen-activated protein kinase (p38 MAPK) pathway activation, which leads to inhibition of platelet-derived growth factor (PDGF)-induced VEGF gene expression, and other redoxinsensitive mechanisms $(171,172)$. While these effects have been seen with a range of polyphenols, the cellular response and its intensity may vary between phenolic compounds $(142,158)$. In addition, it is important to note that the concentrations used in many of these experiments are in the micromolar range.

\section{Bioavailability of (Poly)phenolics}

Polyphenols are characterized by very low bioavailability, with $<1 \%$ of the ingested amount reaching the plasma (162, 173176); concentrations in human plasma usually peak at $0.5-2 \mathrm{~h}$ after ingestion, falling to near baseline levels within 8-12 h (177). Maximum concentrations of polyphenols found in the blood after consumption of polyphenol-rich foods or beverages tend to be around $0.1-1 \mu \mathrm{M}$. This is in stark contrast to the concentrations regularly used in vitro, where supra-physiological concentrations of individual polyphenols or extracts tend to be in the micromolar range $(151,160,178)$.

Numerous polyphenols have been detected in the plasma at concentrations around $1 \mu \mathrm{M}$ in their native intact forms (glucosides), as an effect of fast absorption in the stomach; these are rapidly excreted (179). Anthocyanin glycosides pass through the stomach and are hydrolyzed in the small intestine or by colon microbiota (180). Liberated aglycones are very unstable and undergo further degradation to simple phenolic acids and aldehydes at neutral $\mathrm{pH}$. Smaller phenolic species and other metabolites have greater chemical stability in the physiological environment than anthocyanins, suggesting that the metabolites and not the parent compounds might be present in the plasma at much higher concentrations and could, therefore, play an important role in physiological effects (162). There needs now to be a concerted effort to identify the in vivo metabolite profile derived from given polyphenols to guide more appropriate in vitro experiments that mimic metabolite composition and concentration. This is a major limitation of in vitro experiments that utilize crude extracts.

\section{In Vitro and In Vivo Animal Studies}

There are three major mechanisms by which (poly)phenols might impact on cardiovascular disease, acting as antioxidants, antiinflammatory agents, and/or anti-thrombotic agents.

The high levels of polyphenolics contribute to the highantioxidant capacity in fruit and vegetables $(181,182)$ and extracts from plants or fruits with high-antioxidant capacity have powerful free radical scavenging activity in vitro. Apples are a rich source of polyphenols, including chlorogenic acid, epicatechin, procyanidin $\mathrm{B}_{2}$, phloretin, and quercetin. The antioxidant capacity, determined by a ferric reducing ability of plasma (FRAP) assay, has been shown to vary between apple genotype, and has been demonstrated to relate directly to the polyphenol content of the fruit (182). Similarly, currants, rich in vanillic acid, have shown a similar pattern, using the 1,1-diphenyl-2-picrylhydrazyl (DPPH') radical scavenging assay (183). Meanwhile, the flavonols, quercetin and rutin, are potent scavengers of peroxynitrite, the highly noxious RNS formed by the reaction between superoxide and NO (184). Peroxynitrite has been shown to convert LDL to ox-LDL, key to the development of atherosclerosis, and to oxidize $\alpha$-tocopherol (185). Few, if any of these in vitro experiments use concentrations that equate to those likely to be bioavailable through oral ingestion; so, these findings should be viewed with caution.

The anti-atherogenic effects of the polyphenolics include preventing lipid peroxidation (186) and uptake of ox-LDL by macrophages (187), increasing NO bioavailability $(188,189)$, and decreasing activation of redox-sensitive genes (190). Polyphenolic compounds present in pomegranate juice, red wine, and grapes prevent ox-LDL deposition in the vascular wall. Purple grape juice can both decrease LDL oxidation and flow-mediated vasodilation in patients with coronary artery disease (191). Resveratrol, cinnamic and hydroxycinnamic acids, and cyanidin present in these sources can increase expression of eNOS $(188,189,192)$.

Resveratrol, a stilbene found in red or purple grapes, has also been shown to have potent anti-inflammatory properties. Vascular cell adhesion molecule-1 (VCAM-1), E-selectin, and intracellular adhesion molecule-1 (ICAM-1) are all markers of inflammation that are down-regulated endothelial cells, cultured in the presence of non-physiological concentrations of resveratrol $(1-100 \mu \mathrm{M})$ (193). Moreover, resveratrol has been shown to inhibit lipopolysaccharide (LPS)-induced monocyte adhesion to cultured endothelial cells (193). However, many of the positive aspects of the results obtained so far with resveratrol are tempered 
by the fact that the plasma concentration of resveratrol is thought to be very low (picomolar to nanomolar), mainly because of its rapid metabolism in the gut. To reach the concentrations used in many experiments, $25-50 \mathrm{mg}$ of resveratrol would need to be consumed, the equivalent of drinking 20 glasses of red wine a day $(194,195)$. It is somewhat difficult to explain, therefore, how the acute effects of cigarette smoking on endothelial dysfunction can be reversed by direct antioxidant activity attributed to a single glass of red wine, irrespective of alcohol content (196). Given the above information, it is unlikely that the results are due solely to resveratrol, but they might nevertheless be due to the combined effects of antioxidants in red wine. The same paradigm might also apply to fruit and vegetable consumption; perhaps a single component is not wholly responsible for the beneficial effects seen. Alternatively, the antioxidant benefits of resveratrol in vivo might be entirely driven by stimulation of antioxidant signaling pathways (e.g., activation of the Nrf2/ARE pathway), requiring substantially lower concentrations to be effective.

Delphinidin, an anthocyanin found in berries, has antiapoptotic properties in cultured endothelial cells; it is thought that NO may be involved, as this effect is prevented in the presence of NOS inhibitors, leading to the suggestion that delphinidin may exhibit cardioprotection by preventing endothelial cell apoptosis (197). The anthocyanins have strong anti-thrombotic activities (198, 199): anthocyanins found in fruit and vegetables can inhibit P-selectin expression, an adhesion molecule involved in platelet activation. Resting, TRAP-activated, $\mathrm{H}_{2} \mathrm{O}_{2}$-stressed, and adrenaline pre-activated platelets were inhibited by the anthocyanins in vitro, whereas collagen- and ADP-activation are not affected (198). It is plausible that anthocyanins in purple grape juice are at least partly responsible for its ability to inhibit platelet function both in vitro and in vivo, through an increase in NO production and a decrease in superoxide generation. Analysis of purple grape juice using high-performance liquid chromatography (HPLC) found that fractions containing high amounts of proanthocyanins were most effective in preventing lipid peroxidation $(199,200)$.

Quercetin has anti-hypertensive properties and reduces cardiac hypertrophy in animal models. Hypertension has been shown to be reversed in spontaneously hypertensive rats and Goldblatt hypertensive rats, but not in normotensive controls $(201,202)$. In addition, cardiac hypertrophy in hypertensive rats was reduced in animals fed a quercetin-rich diet $(203,204)$. A wide range of studies have indicated that quercetin has the capability to act as an antioxidant in vivo through altered gene transcription (205-208). These in vivo experiments are likely to be a more reliable source of mechanistic information than in vitro experiments involving crude extracts and isolated compounds, often at inappropriate concentrations.

\section{Clinical Studies and Trials}

Epidemiological studies appear to show an association between high-flavonoid intake and cardiovascular outcomes. For example, the Zupthen Elderly study found a significant inverse relationship between flavonoid intake and coronary heart disease after 5 years, but after 10 years this relationship was no longer significant (209, 210). Moreover, the Rotterdam study found a significant inverse relationship between total flavonoid intake from the diet, in particular, black tea (which is rich in flavon-3-ols in particular), with myocardial infarction incidence (211).

A meta-analysis published in 2008 reported on 133 placebocontrolled trials on specific flavonoids and flavonoid-rich foods (212). None of the studies reported on morbidity or mortality; instead, they measured one or more of a range of physiological measures (blood pressure, endothelial function) and markers (e.g., LDL) of cardiovascular disease. The heterogeneity of the studies made firm conclusions difficult to reach, but certain trends were identified in this meta-analysis. Measures of flow-mediated dilatation - an indicator of endothelial function - were universally improved in the acute phase, irrespective of the epicatechin dose administered, but there was little effect of flavonoid interventions on either blood pressure or LDL cholesterol (212).

More recent trials on specific polyphenols or food types have lent weight to the concept that there might be merit in polyphenol supplementation in cardiovascular disease prevention. In a modest placebo-controlled crossover clinical trial involving 93 obese or overweight men with metabolic syndrome traits, quercetin was found to reduce systolic blood pressure by $\sim 3 \mathrm{mmHg}$, an effect that was more pronounced in the sub-group of patients with hypertension (213). Despite the low-plasma concentrations of quercetin measured in this study (71-269 nM) and a lack of significant increase in plasma antioxidant capacity, there was also a significant increase in HDL and a reduction in the concentration of pro-atherogenic ox-LDL.

However, the studies that have captured the imagination of the press and public the most are those involving the benefits of tea, chocolate, and red wine; it is evidently attractive for healthy nutritional interventions to also be pleasurable. The phenolic content of chocolate and both green and black tea is dominated by flavan-3-ols (catechin and epicatechin) and isoflavones. Dietary intake of cocoa or chocolate is inversely associated with carotid atherosclerosis (214) and calcified plaque development (215). In a double-blind placebo-controlled trial with flavonoid-enriched chocolate in patients with type 2 diabetes, there was an improvement in carotid vascular function (216). Similarly, isoflavonespecific intervention trials in healthy individuals have indicated some benefits with respect to endothelial function, blood pressure, and arterial stiffness. However, the longest trial with isoflavones (2.7-year follow up) showed no benefit, as measured by common carotid artery intima-medial thickness.

Red wine is a flavonoid-rich drink that has long been associated with cardiovascular benefit. Its notoriety in this regard was triggered by the suggestion that high red wine consumption in France provided a plausible explanation for the so-called French paradox - the remarkably low risk of cardiovascular mortality among the French population, irrespective of high-saturated fat consumption and smoking rates. However simplistic the original suggestion was, the potential merits of red wine have been supported by data from the Copenhagen City Heart Study, in which individuals who drank moderate amounts (three to five glasses per day) of red wine were at substantially lower risk (RR - 0.51) of cardiovascular mortality than those who never drank wine (217). By contrast, there was no significant benefit from drinking beer and a substantial increase in risk associated with drinking spirits. 
Several recent intervention studies have interrogated the association with a view to establishing mechanism; the findings generally confirm beneficial effects, most likely conveyed by polyphenol constituents [but not necessarily resveratrol (218)]. However, the data regarding impact of red wine on antioxidant capacity (219) or platelet activity (220) are unconvincing, compared to benefits mediated via improvements in plasma lipoprotein profile (221, 222), NO concentration (223), and inflammatory markers [most notably chemokine $\mathrm{C}-\mathrm{C}$ motif ligand 5 (CCL-5) (224) and NF- $\kappa \mathrm{B}$ (219)]. Interestingly, there is a pattern emerging to suggest that alcohol-free red wine might convey enhanced benefits over red wine itself $(222,223)$.

Although the results from intervention studies are not universally supportive of benefit of polyphenol-rich foods and drinks, there is reason for optimism regarding potential benefits with respect to several markers of key elements (e.g., endothelial function, platelet function) central to the atherothrombotic process. Antioxidant activity is not necessarily a factor. Data relating to red wine consumption are perhaps the most convincing, with an association identified between moderate red wine consumption and cardiovascular mortality. However, it is also clear that the limited bioavailability of beneficial flavonoids is universally low (typically in the nanomolar range) and that a direct antioxidant effect is unlikely to drive the benefits seen. This does not, however, preclude the possibility that the beneficial effects are mediated by an adaptive response that includes up-regulation of endogenous antioxidant systems. In addition, it is apparent that flavonoids have subtle, antioxidant-independent effects (e.g., reduced inflammation, reduced insulin resistance), which might be at least as important as any antioxidant activity. It is also important to note that flavonoids are typically bitter to taste and that the strategy often employed in nature (berries) and in food production (chocolate) is to modulate the bitter taste with sugar (berries, chocolate) or alcohol (red wine). Inevitably, therefore, there is an element of risk balance between the benefits of flavonoids and the potential detrimental effects of associated ingredients in tasty foods and drinks.

\section{Minerals}

A number of minerals have the potential for antioxidant activity in vivo, not through direct scavenging of free radicals (indeed, many transition metal ions are considered to be pro-oxidant), but instead through their requirement for antioxidant enzyme function. The requirement for metal ions, such as copper, zinc (cofactors for cytoplasmic SOD-1), manganese (cofactor for mitochondrial SOD-2), and selenium (cofactor for GPx and thioredoxins), is generally at trace levels that are easily obtainable through the diet. Deficiencies are, therefore, rare, but can occur in cases of malabsorption or in geographical regions where these minerals are deficient or absent in the soil. Of the minerals named above, selenium is the most recognized to be deficient in some populations, and to have a link to cardiovascular (and other) diseases (225), potentially on account of reduced antioxidant capacity.

\section{Selenium}

Selenium is required at trace levels and excessive supplementation can lead to toxicity (selenosis). Much of the work relating to selenium has centered on its role in cancer prevention, but a number of studies have focused on cardiovascular disease or have included cardiovascular outcomes as a sub-set of all-cause mortality. While observational studies suggest an inverse relationship between selenium levels in the body and cardiovascular risk (226), placebo-controlled large trials failed to find a significant effect of selenium supplements for CVD events (fatal and non-fatal; RR 1.03) (227), suggesting that selenium supplementation is ineffective in this setting. Indeed, the findings of the Cochrane review on antioxidants and all-cause mortality indicate that there is no evidence for reduced mortality with selenium supplementation. In this sense, the story for selenium mirrors those for many of the antioxidants above in that the results of observational studies are not supported by those from placebo-controlled trials. Once again, the lack of agreement between the two approaches might simply reflect the heterogeneity of the controlled trial population with respect to selenium levels; only a small sub-set might be deficient and likely to benefit from the intervention.

Keshan disease is a specific endemic cardiomyopathy has also been linked with selenium deficiency. The name relates to the region of China associated with an unusually high incidence of the disease, first identified in 1935. However, cases are found in a range of areas, predominantly in China, where the soil is deficient in selenium. The symptoms include acute or chronic episodes of cardiogenic shock and/or heart failure. Although the cause has not yet been fully characterized, animal studies suggest a possible mechanism involving reduced expression of the antioxidant enzyme, GPx1, leading to increased virulence of viruses associated with myocarditis (228). Clinical studies suggest an extra layer of complexity surrounding Keshan disease on account of decreased GPx1 activity in individuals with both selenium deficiency and a specific leucine-containing GPx1 allele (229). The link to selenium deficiency has long been recognized (230) and selenium supplementation trials have shown a striking impact on Keshan disease development and disease-related deaths, possibly on account of increased GPx activity (231). Here, at least, there is clear evidence of a substantial beneficial effect of a supplement that has the potential to increase antioxidant defense via GPx enzymes.

\section{Repurposed Drugs as Antioxidants $\mathrm{N}$-Acetylcysteine}

$\mathrm{N}$-Acetylcysteine (NAC) has sparked interest in the cardiovascular field on account of its reputation as an antioxidant. NAC is a drug that is licensed for use in several clinical settings, but it is also feely available as an oral supplement through health food outlets, although it is not generally considered to be a dietary component. In reality, its antioxidant activity and oral bioavailability is too low to merit consideration as an antioxidant in vivo [reviewed in Ref. (232)], but it nevertheless merits inclusion in this review on account of its ability to serve as a substrate for the synthesis of the critical ubiquitous intracellular antioxidant, GSH (233). GSH is central to a variety of important processes, including detoxification, and its synthesis, utilization, and redox status is under the regulation of a battery of enzymes, underlining its importance to cell function. GSH can be depleted in cells for a variety of reasons, most notably in hepatocytes as a result of paracetamol overdose, and also in association with atherosclerosis (41). NAC 
was originally designed as a means of effectively delivering substrate (cysteine) to the rate-limiting enzyme (glutamyl-cysteine ligase) for GSH synthesis. Although the mechanism by which NAC achieves this goal is not yet fully understood, it is certainly an effective remedy in patients suffering from paracetamol overdose (234). NAC is also used in some pulmonary conditions, but from an antioxidant perspective, it has received attention as a potential means of protecting against oxidative stress-induced radiocontrast nephropathy and as a possible alternative anti-thrombotic agent in diabetes (232). The latter use is the most relevant to this review and is supported by several in vitro and in vivo studies, suggesting that there is some merit in this concept. NAC has been shown to have a significant impact on blood pressure in patients with type 2 diabetes (235) and, most recently, a small clinical study has indicated that oral NAC supplementation in patients with type 2 diabetes reduces platelet-monocyte interaction (236), which is recognized to be a marker and potential mediator of cardiovascular disease. Importantly, the beneficial effect was most prominent in those deficient in GSH at baseline, indicating that, like vitamin $\mathrm{C}$, cellular GSH is under strict regulation and providing more substrate for its synthesis to replenish cells is ineffectual. That said, GSH is well known to be depleted in diabetes (237), and in vitro studies indicate that NAC can replenish platelet GSH (238). Therefore, NAC might well present an effective strategy in this high-risk patient group, especially given its beneficial effect in blood vessels as well as platelets. Larger trials are merited to test whether these findings translate into improved cardiovascular outcome in patients at risk of cardiovascular disease and in patients with diabetes in particular.

\section{Allopurinol}

Allopurinol is an inhibitor of the enzyme, XO, which catalyzes the conversion of hypoxanthine, via xanthine, to uric acid. As such, allopurinol is an effective treatment for gout, caused by the accumulation of uric acid crystals in the joints. However, allopurinol is also considered to be a XO-specific antioxidant because the enzyme uses molecular oxygen as the electron acceptor during the oxidation process, generating ROS as a by-product. This has relevance to a number of diseases because $\mathrm{XO}$ predominantly exists in its dehydrogenase form, which does not generate ROS; conversion of the dehydrogenase to XO can be caused by oxidative modification of the enzyme or irreversible proteolysis. The amount of $\mathrm{XO}$-derived ROS is dependent on the preponderance of $\mathrm{XO}$ as well as the availability of substrate (hypoxanthine and xanthine). In heart failure, hypoxanthine and xanthine concentrations increase as a result of cellular damage and there is also the potential for oxidative modification to generate more $\mathrm{XO}$ in this disease. As a result, serum uric acid is recognized to be an independent marker of heart failure severity (239) and a possible surrogate marker of oxidative stress in heart failure. Animal studies indicate that allopurinol, among other inhibitors of XO (e.g., oxypurinol), effectively reduce mortality and improve left ventricular function in models of heart failure $(240,241)$. Some clinical studies using intravenous or intracoronary infusion of $\mathrm{XO}$ inhibitors support these findings $(242,243)$, but the majority of the randomized clinical trials (244-249) have failed to replicate the beneficial findings in animal studies, although there are some hints of improvement in ejection fraction [reviewed in Ref. (250)]. The lack of consistency between the animal and clinical studies is frustrating, but no doubt highlights the complexity of the human disease profile, in which XO-derived ROS are only a contributory element.

\section{Conclusion}

Given that oxidative stress is a key player at various levels in the atherogenic process, it is a reasonable assumption that antioxidant therapy would be an effective therapy in this setting. Indeed, puzzling anomalies in epidemiological data (the French paradox) have been attributed to high-antioxidant ingestion specific to a given population and in vitro studies using relatively high concentrations of a wide range of antioxidants support the notion that antioxidants have protective effects. However, associations between plasma concentrations of antioxidant vitamins (A, C, and $\mathrm{E}$ ) and protection against cardiovascular disease have proved elusive and large intervention trials with these vitamins have failed to conclusively show any benefit. In hindsight, the failure of antioxidant vitamins to show benefit is unsurprising for a range of fundamental reasons that expose several generalizations relating to oxidative stress and antioxidants. First, ROS are not universally harmful; repeated, low-level exposure to ROS is a vital trigger for up-regulation of endogenous antioxidants. Second, redox is a question of balance and the concept of flooding cells with dietary antioxidants to combat oxidative stress is flawed, not only because there are powerful physiological processes in place to ensure that these agents are kept within reasonably strict limits, but also because driving cells into a highly reducing state is likely to be harmful too. Third, many of the diet-derived antioxidants (e.g., polyphenols) are very effectively screened out by the gut or rapidly metabolized and excreted. Plasma concentrations are typically in the nanomolar range - too low to have a direct impact on antioxidant capacity. Paradoxically, it is some of these dietary micronutrients that are perhaps the most promising in terms of cardiovascular outcome, but they should not be considered to be direct antioxidants in this regard. Instead, polyphenolic compounds, or more likely the metabolites that they yield, probably act as mild toxins to drive endogenous defense mechanisms, including up-regulation of a battery of cellular antioxidant systems (168). The irony is that the direct antioxidant activity of polyphenols is almost irrelevant in their protective properties; instead, it is their toxic properties that could prove decisive in determining their efficacy in this regard. Achieving a better understanding of the mechanisms by which polyphenols work is essential in driving the paradigm shift away from the concept that foods high in antioxidants will improve cardiovascular health. Perhaps the focus should be on the diversity and frequency of exposure to dietary polyphenols that should be the focus of public health messages rather than amount.

\section{Fruit and Vegetables vs. Supplements}

Plants synthesize an enormous variety of chemicals with powerful antioxidant properties, and many clinical studies support the notion that increased consumption of fruit and vegetables have beneficial effects with respect to various markers of cardiovascular disease $(84,251)$. It is a reasonable extrapolation to suggest that 
the benefits of fruit and vegetables might be attributable to the most abundant antioxidants that are often present in these foods, namely, vitamins A, C, and E. However, the benefits of vitaminrich foods have not been matched by large-scale supplement studies, perhaps suggesting that it is not these agents that are responsible to the beneficial effects, but some of the micronutrients that accompany the antioxidant vitamins in these foods. Alternatively, it might be that the whole is greater than the sum of its parts and that there is a synergistic effect of the rich combination of micronutrients and vitamins in fruit and vegetable that bring about the benefit - an effect that is lost in isolated supplements or in multivitamin formulations. Either way, the lack of alignment of results from whole fruit and vegetables compared with vitamin supplements would suggest that vitamins alone do not constitute the answer with respect to antioxidant benefits of certain foods in cardiovascular disease.

\section{In Vitro and In Vivo Studies}

Why then, the dichotomy between in vitro (e.g., cell culture) and small-scale clinical studies compared with larger clinical trials? The answer to this question is vexing, but the reason is likely to lie in the detail of experimental procedures. For example, many in vitro experiments use concentrations of antioxidants that are much higher (sometimes orders of magnitude greater) than those that are likely to be found in vivo after oral ingestion. Second, it is clear that the digestive system has an enormous impact on the survival or otherwise of antioxidants; for example, large polyphenolic compounds undergo significant hydrolysis and it is widely acknowledged that only small phenolic compounds pass into the plasma. Third, the combination of antioxidants that one might receive from ingestion of fruit and vegetables could be crucial in providing significant benefit - telling in this regard are the data from studies that demonstrate a benefit of elevated vitamin $\mathrm{C}$ from increased fruit and vegetable ingestion, but not from vitamin $\mathrm{C}$ supplements alone. It is entirely plausible that the plasma vitamin $\mathrm{C}$ measured in the fruit and vegetable studies was a marker of the dietary intervention, but a red herring with respect to causality. In addition, there may be other benefits of fruit and vegetables beyond antioxidants; plant-derived sterols,

\section{References}

1. Harman D. Aging: a theory based on free radical and radiation chemistry. J Gerontol (1956) 11(3):298-300. doi:10.1093/geronj/11.3.298

2. McCubrey JA, Lahair MM, Franklin RA. Reactive oxygen species-induced activation of the MAP kinase signaling pathways. Antioxid Redox Signal (2006) 8(9-10):1775-89. doi:10.1089/ars.2006.8.1745

3. Yang Y, Bazhin AV, Werner J, Karakhanova S. Reactive oxygen species in the immune system. Int Rev Immunol (2013) 32(3):249-70. doi:10.3109/08830185. 2012.755176

4. Shaw A, Doherty MK, Mutch NJ, MacRury SM, Megson IL. Endothelial cell oxidative stress in diabetes: a key driver of cardiovascular complications? Biochem Soc Trans (2014) 42(4):928-33. doi:10.1042/BST20140113

5. Dai DF, Rabinovitch PS, Ungvari Z. Mitochondria and cardiovascular aging. Circ Res (2012) 110(8):1109-24. doi:10.1161/CIRCRESAHA.111. 246140

6. Ristow M, Schmeisser S. Extending life span by increasing oxidative stress. Free Radic Biol Med (2011) 51(2):327-36. doi:10.1016/j.freeradbiomed.2011. 05.010

7. van Duynhoven J, Vaughan EE, van Dorsten F, Gomez-Roldan V, de Vos $\mathrm{R}$, Vervoort J, et al. Interactions of black tea polyphenols with human gut for example, have a modest impact on plasma LDL levels (252). Finally, the end point that is most important in terms of cardiovascular benefit is reduced mortality due to myocardial infarction and stroke. Cardiovascular events are precipitated by plaque rupture, a process that is perhaps influenced by inflammation within the plaque, but does not necessarily correlate with atherosclerotic load. It is quite possible, therefore, that subtle improvements in endothelial function or lipid peroxidation might not have a great deal of impact on the predisposition to plaque rupture.

Despite a wealth of in vitro and in vivo animal data, the cardiovascular benefits of antioxidant have not yet been proven, particularly with respect to reduced mortality, but there is sufficient evidence in the literature to suggest that there is considerable promise of improving some aspects of cardiovascular health through increased fruit and vegetable consumption. Whether the same is true of isolated antioxidant vitamins, minerals, or polyphenols is less convincing, but as we gain a better understanding of the complexity of the mechanisms involved, there is increased potential to find diet or drug-derived antioxidant agents with beneficial effects, though not necessarily on account of their ability to directly scavenge radicals. Priming the adaptive response on account of low-grade, repeated toxicity, in a process with some parallels to those now thought to be important in underpinning the benefits of exercise, looks like it might hold more promise than attempting to flood the system with antioxidants.

In conclusion, antioxidants should not be considered to be either a panacea or a false hope with respect to cardiovascular disease prevention. To achieve success, however, it is necessary for studies to be carefully designed; the choice of antioxidant should be informed by the target disease, the confirmed role of oxidative stress, and the relevant cellular compartment, as well as the potential antioxidant deficiencies in the target population.

\section{Acknowledgments}

KG's Ph.D. was funded by the EU North Sea Region Programme (www.ClimaFruit.com), a European Regional Development Fund initiative.

microbiota: implications for gut and cardiovascular health. Am J Clin Nutr (2013) 98(6 Suppl):1631S-41S. doi:10.3945/ajcn.113.058263

8. Russell WR, Scobbie L, Labat A, Duthie GG. Selective bio-availability of phenolic acids from Scottish strawberries. Mol Nutr Food Res (2009) 53(Suppl 1):S85-91. doi:10.1002/mnfr.200800302

9. Dauchet L, Ferrieres J, Arveiler D, Yarnell JW, Gey F, Ducimetiere P, et al. Frequency of fruit and vegetable consumption and coronary heart disease in France and Northern Ireland: the PRIME study. Br J Nutr (2004) 92(6):963-72. doi:10.1079/BJN20041286

10. Liu S, Manson JE, Lee IM, Cole SR, Hennekens CH, Willett WC, et al. Fruit and vegetable intake and risk of cardiovascular disease: the Women's Health Study. Am J Clin Nutr (2000) 72(4):922-8.

11. Ness AR, Powles JW. Fruit and vegetables, and cardiovascular disease: a review. Int J Epidemiol (1997) 26(1):1-13. doi:10.1093/ije/26.1.1

12. Todd S, Woodward M, Tunstall-Pedoe H, Bolton-Smith C. Dietary antioxidant vitamins and fiber in the etiology of cardiovascular disease and all-causes mortality: results from the Scottish heart health study. Am J Epidemiol (1999) 150(10):1073-80. doi:10.1093/oxfordjournals.aje.a009931

13. Appel LJ, Moore TJ, Obarzanek E, Vollmer WM, Svetkey LP, Sacks FM, et al. A clinical trial of the effects of dietary patterns on blood pressure. N Engl J Med (1997) 336(16):1117-24. doi:10.1056/NEJM199704173361601 
14. Le Brocq M, Leslie SJ, Milliken P, Megson IL. Endothelial dysfunction: from molecular mechanisms to measurement, clinical implications, and therapeutic opportunities. Antioxid Redox Signal (2008) 10(9):1631-74. doi:10.1089/ars. 2007.2013

15. Araujo FB, Barbosa DS, Hsin CY, Maranhao RC, Abdalla DS. Evaluation of oxidative stress in patients with hyperlipidemia. Atherosclerosis (1995) 117(1):61-71. doi:10.1016/0021-9150(94)05558-Z

16. Biswas SK, de Faria JB. Which comes first: renal inflammation or oxidative stress in spontaneously hypertensive rats? Free Radic Res (2007) 41(2):216-24. doi:10.1080/10715760601059672

17. Paravicini TM, Touyz RM. Redox signaling in hypertension. Cardiovasc Res (2006) 71(2):247-58. doi:10.1016/j.cardiores.2006.05.001

18. West IC. Radicals and oxidative stress in diabetes. Diabet Med (2000) 17(3):171-80. doi:10.1046/j.1464-5491.2000.00259.x

19. Bakker SJ, RG IJ, Teerlink T, Westerhoff HV, Gans RO, Heine RJ. Cytosolic triglycerides and oxidative stress in central obesity: the missing link between excessive atherosclerosis, endothelial dysfunction, and beta-cell failure? Atherosclerosis (2000) 148(1):17-21. doi:10.1016/S0021-9150(99)00329-9

20. Chalmers A. Smoking and oxidative stress. Am J Clin Nutr (1999) 69(3):572.

21. Megson IL, Haw SJ, Newby DE, Pell JP. Association between exposure to environmental tobacco smoke and biomarkers of oxidative stress among patients hospitalised with acute myocardial infarction. PLoS One (2013) 8(12):e81209. doi:10.1371/journal.pone.0081209

22. Bernhard D, Wang XL. Smoking, oxidative stress and cardiovascular diseases do anti-oxidative therapies fail? Curr Med Chem (2007) 14(16):1703-12. doi:10.2174/092986707781058959

23. Miller MR, Borthwick SJ, Shaw CA, McLean SG, McClure D, Mills NL, et al. Direct impairment of vascular function by diesel exhaust particulate through reduced bioavailability of endothelium-derived nitric oxide induced by superoxide free radicals. Environ Health Perspect (2009) 117(4):611-6. doi:10.1289/ehp.0800235

24. Newby DE, Mannucci PM, Tell GS, Baccarelli AA, Brook RD, Donaldson K, et al. Expert position paper on air pollution and cardiovascular disease. Eur Heart J (2015) 36(2):83-93. doi:10.1093/eurheartj/ehu458

25. Halliwell B. Biochemistry of oxidative stress. Biochem Soc Trans (2007) 35(Pt 5):1147-50. doi:10.1042/BST0351147

26. Cai H, Harrison DG. Endothelial dysfunction in cardiovascular diseases: the role of oxidant stress. Circ Res (2000) 87(10):840-4. doi:10.1161/01.RES. 87.10 .840

27. Cines DB, Pollak ES, Buck CA, Loscalzo J, Zimmerman GA, McEver RP, et al. Endothelial cells in physiology and in the pathophysiology of vascular disorders. Blood (1998) 91(10):3527-61.

28. Gryglewski RJ, Palmer RM, Moncada S. Superoxide anion is involved in the breakdown of endothelium-derived vascular relaxing factor. Nature (1986) 320(6061):454-6. doi:10.1038/320454a0

29. Hayashi Y, Sawa Y, Nishimura M, Fukuyama N, Ichikawa H, Ohtake S, et al. Peroxynitrite, a product between nitric oxide and superoxide anion, plays a cytotoxic role in the development of post-bypass systemic inflammatory response. Eur J Cardiothorac Surg (2004) 26(2):276-80. doi:10.1016/j.ejcts. 2004.03.033

30. Radi R, Beckman JS, Bush KM, Freeman BA. Peroxynitrite-induced membrane lipid peroxidation: the cytotoxic potential of superoxide and nitric oxide. Arch Biochem Biophys (1991) 288(2):481-7. doi:10.1016/0003-9861(91)90224-7

31. Radi R, Beckman JS, Bush KM, Freeman BA. Peroxynitrite oxidation of sulfhydryls. The cytotoxic potential of superoxide and nitric oxide. J Biol Chem (1991) 266(7):4244-50.

32. Ayala A, Munoz MF, Arguelles S. Lipid peroxidation: production, metabolism, and signaling mechanisms of malondialdehyde and 4-hydroxynonenal. Oxid Med Cell Longev (2014) 2014:360438. doi:10.1155/2014/360438

33. Csordas A, Bernhard D. The biology behind the atherothrombotic effects of cigarette smoke. Nat Rev Cardiol (2013) 10(4):219-30. doi:10.1038/nrcardio. 2013.8

34. Lankin VZ, Lisina MO, Arzamastseva NE, Konovalova GG, Nedosugova LV, Kaminnyi AI, et al. Oxidative stress in atherosclerosis and diabetes. Bull Exp Biol Med (2005) 140(1):41-3. doi:10.1007/s10517-005-0406-z

35. Aikawa M, Sugiyama S, Hill CC, Voglic SJ, Rabkin E, Fukumoto Y, et al. Lipid lowering reduces oxidative stress and endothelial cell activation in rabbit atheroma. Circulation (2002) 106(11):1390-6. doi:10.1161/01.CIR. $0000028465.52694 .9 \mathrm{~B}$
36. Alexander RW. Theodore cooper memorial lecture. Hypertension and the pathogenesis of atherosclerosis. Oxidative stress and the mediation of arterial inflammatory response: a new perspective. Hypertension (1995) 25(2):155-61. doi:10.1161/01.HYP.25.2.155

37. Libby P. Inflammation in atherosclerosis. Nature (2002) 420(6917):868-74. doi:10.1038/nature01323

38. Ross R. Atherosclerosis - an inflammatory disease. N Engl J Med (1999) 340(2):115-26. doi:10.1056/NEJM199901143400207

39. Kaplan M, Aviram M. Oxidized low density lipoprotein: atherogenic and proinflammatory characteristics during macrophage foam cell formation. An inhibitory role for nutritional antioxidants and serum paraoxonase. Clin Chem Lab Med (1999) 37(8):777-87. doi:10.1515/CCLM.1999.118

40. Newby DE. Triggering of acute myocardial infarction: beyond the vulnerable plaque. Heart (2010) 96(15):1247-51. doi:10.1136/hrt.2009.175141

41. Biswas SK, Newby DE, Rahman I, Megson IL. Depressed glutathione synthesis precedes oxidative stress and atherogenesis in Apo-E(-/-) mice. Biochem Biophys Res Commun (2005) 338(3):1368-73. doi:10.1016/j.bbrc.2005.10.098

42. Rahman I, Biswas SK, Jimenez LA, Torres M, Forman HJ. Glutathione, stress responses, and redox signaling in lung inflammation. Antioxid Redox Signal (2005) 7(1-2):42-59. doi:10.1089/ars.2005.7.1

43. Martinez-Cayuela M. Oxygen free radicals and human disease. Biochimie (1995) 77(3):147-61. doi:10.1016/0300-9084(96)88119-3

44. Curtin JF, Donovan M, Cotter TG. Regulation and measurement of oxidative stress in apoptosis. J Immunol Methods (2002) 265(1-2):49-72. doi:10.1016/ S0022-1759(02)00070-4

45. Profumo E, Buttari B, Saso L, Rigano R. Pleiotropic effects of statins in atherosclerotic disease: focus on the antioxidant activity of atorvastatin. Curr Top Med Chem (2014) 14(22):2542-51. doi:10.2174/1568026614666 141203130324

46. Moon GJ, Kim SJ, Cho YH, Ryoo S, Bang OY. Antioxidant effects of statins in patients with atherosclerotic cerebrovascular disease. J Clin Neurol (2014) 10(2):140-7. doi:10.3988/jcn.2014.10.2.140

47. Rosenson RS. Statins in atherosclerosis: lipid-lowering agents with antioxidant capabilities. Atherosclerosis (2004) 173(1):1-12. doi:10.1016/S0021-9150(03) 00239-9

48. von Schacky C, Fischer S, Weber PC. Long-term effects of dietary marine omega-3 fatty acids upon plasma and cellular lipids, platelet function, and eicosanoid formation in humans. J Clin Invest (1985) 76(4):1626-31. doi:10. 1172/JCI112147

49. Anderson EJ, Thayne KA, Harris M, Shaikh SR, Darden TM, Lark DS, et al. Do fish oil omega-3 fatty acids enhance antioxidant capacity and mitochondrial fatty acid oxidation in human atrial myocardium via PPARgamma activation? Antioxid Redox Signal (2014) 21(8):1156-63. doi:10.1089/ars.2014.5888

50. Hajianfar H, Paknahad Z, Bahonar A. The effect of omega-3 supplements on antioxidant capacity in patients with type 2 diabetes. Int J Prev Med (2013) 4(Suppl 2):S234-8.

51. Linseisen J, Hoffmann J, Lienhard S, Jauch KW, Wolfram G. Antioxidant status of surgical patients receiving TPN with an omega-3-fatty acidcontaining lipid emulsion supplemented with alpha-tocopherol. Clin Nutr (2000) 19(3):177-84. doi:10.1054/clnu.1999.0096

52. Gilbert K, Bernier J, Godbout R, Rousseau G. Resolvin D1, a metabolite of omega-3 polyunsaturated fatty acid, decreases post-myocardial infarct depression. Mar Drugs (2014) 12(11):5396-407. doi:10.3390/md12115396

53. Kim TH, Kim GD, Jin YH, Park YS, Park CS. Omega- 3 fatty acid-derived mediator, resolvin E1, ameliorates 2,4-dinitrofluorobenzene-induced atopic dermatitis in NC/Nga mice. Int Immunopharmacol (2012) 14(4):384-91. doi:10. 1016/j.intimp.2012.08.005

54. Seki H, Tani Y, Arita M. Omega-3 PUFA derived anti-inflammatory lipid mediator resolvin E1. Prostaglandins Other Lipid Mediat (2009) 89(3-4):126-30. doi:10.1016/j.prostaglandins.2009.03.002

55. Arita M, Bianchini F, Aliberti J, Sher A, Chiang N, Hong S, et al. Stereochemical assignment, antiinflammatory properties, and receptor for the omega-3 lipid mediator resolvin E1. J Exp Med (2005) 201(5):713-22. doi:10.1084/jem. 20042031

56. Watkins ML, Erickson JD, Thun MJ, Mulinare J, Heath CW Jr. Multivitamin use and mortality in a large prospective study. Am J Epidemiol (2000) 152(2):149-62. doi:10.1093/aje/152.2.149

57. Holmquist C, Larsson S, Wolk A, de Faire U. Multivitamin supplements are inversely associated with risk of myocardial infarction in men and 
women - Stockholm heart epidemiology program (SHEEP). J Nutr (2003) 133(8):2650-4.

58. Muntwyler J, Hennekens CH, Manson JE, Buring JE, Gaziano JM. Vitamin supplement use in a low-risk population of US male physicians and subsequent cardiovascular mortality. Arch Intern Med (2002) 162(13):1472-6. doi:10. 1001/archinte.162.13.1472

59. Neuhouser ML, Wassertheil-Smoller S, Thomson C, Aragaki A, Anderson GL, Manson JE, et al. Multivitamin use and risk of cancer and cardiovascular disease in the women's health initiative cohorts. Arch Intern Med (2009) 169(3):294-304. doi:10.1001/archinternmed.2008.540

60. Park SY, Murphy SP, Wilkens LR, Henderson BE, Kolonel LN. Multivitamin use and the risk of mortality and cancer incidence: the multiethnic cohort study. Am J Epidemiol (2011) 173(8):906-14. doi:10.1093/aje/kwq447

61. Sesso HD, Christen WG, Bubes V, Smith JP, MacFadyen J, Schvartz M, et al. Multivitamins in the prevention of cardiovascular disease in men: the physicians' health study II randomized controlled trial. JAMA (2012) 308(17):1751-60. doi:10.1001/jama.2012.14805

62. Moyer VA. Vitamin, mineral, and multivitamin supplements for the primary prevention of cardiovascular disease and cancer: U.S. preventive services task force recommendation statement. Ann Intern Med (2014) 160(8):558-64. doi:10.7326/M14-0198

63. Bjelakovic G, Nikolova D, Gluud LL, Simonetti RG, Gluud C. Antioxidant supplements for prevention of mortality in healthy participants and patients with various diseases. Cochrane Database Syst Rev (2012) 3:CD007176. doi:10. 1002/14651858.CD007470.pub2

64. Padayatty SJ, Katz A, Wang Y, Eck P, Kwon O, Lee JH, et al. Vitamin C as an antioxidant: evaluation of its role in disease prevention. J Am Coll Nutr (2003) 22(1):18-35. doi:10.1080/07315724.2003.10719272

65. Nishikimi M, Fukuyama R, Minoshima S, Shimizu N, Yagi K. Cloning and chromosomal mapping of the human nonfunctional gene for L-gulonogamma-lactone oxidase, the enzyme for L-ascorbic acid biosynthesis missing in man. J Biol Chem (1994) 269(18):13685-8.

66. Griffiths HR, Lunec J. Ascorbic acid in the 21st century - more than a simple antioxidant. Environ Toxicol Pharmacol (2001) 10(4):173-82. doi:10. 1016/S1382-6689(01)00081-3

67. Kagan VE, Serbinova EA, Forte T, Scita G, Packer L. Recycling of vitamin E in human low density lipoproteins. J Lipid Res (1992) 33(3):385-97.

68. Levine M, Conry-Cantilena C, Wang Y, Welch RW, Washko PW, Dhariwal KR, et al. Vitamin $C$ pharmacokinetics in healthy volunteers: evidence for a recommended dietary allowance. Proc Natl Acad Sci U S A (1996) 93(8):3704-9. doi:10.1073/pnas.93.8.3704

69. Levine M, Rumsey SC, Wang Y, Park J, Kwon O, Amano N. In situ kinetics: an approach to recommended intake of vitamin C. Methods Enzymol (1997) 281:425-37.

70. Tsukaguchi H, Tokui T, Mackenzie B, Berger UV, Chen XZ, Wang Y, et al. A family of mammalian $\mathrm{Na}$--dependent L-ascorbic acid transporters. Nature (1999) 399(6731):70-5. doi:10.1038/19986

71. Vera JC, Rivas CI, Fischbarg J, Golde DW. Mammalian facilitative hexose transporters mediate the transport of dehydroascorbic acid. Nature (1993) 364(6432):79-82. doi:10.1038/364079a0

72. Duarte TL, Lunec J. Part of the series: from dietary antioxidants to regulators in cellular signalling and gene expression - review: when is an antioxidant not an antioxidant? A review of novel actions and reactions of vitamin C. Free Radic Res (2005) 39(7):671-86. doi:10.1080/10715760500104025

73. Lehr HA, Frei B, Arfors KE. Vitamin C prevents cigarette smoke-induced leukocyte aggregation and adhesion to endothelium in vivo. Proc Natl Acad Sci U S A (1994) 91(16):7688-92. doi:10.1073/pnas.91.16.7688

74. Frei B. Ascorbic acid protects lipids in human plasma and low-density lipoprotein against oxidative damage. Am J Clin Nutr (1991) 54(6 Suppl): 1113S-8S.

75. Maeda N, Hagihara H, Nakata Y, Hiller S, Wilder J, Reddick R. Aortic wall damage in mice unable to synthesize ascorbic acid. Proc Natl Acad Sci U S A (2000) 97(2):841-6. doi:10.1073/pnas.97.2.841

76. Nakata Y, Maeda N. Vulnerable atherosclerotic plaque morphology in apolipoprotein E-deficient mice unable to make ascorbic acid. Circulation (2002) 105(12):1485-90. doi:10.1161/01.CIR.0000012142. 69612.25

77. Wannamethee SG, Lowe GD, Rumley A, Bruckdorfer KR, Whincup PH. Associations of vitamin C status, fruit and vegetable intakes, and markers of inflammation and hemostasis. Am J Clin Nutr (2006) 83(3):567-74.
78. Solzbach U, Hornig B, Jeserich M, Just H. Vitamin C improves endothelial dysfunction of epicardial coronary arteries in hypertensive patients. Circulation (1997) 96(5):1513-9. doi:10.1161/01.CIR.96.5.1513

79. Beckman JA, Goldfine AB, Gordon MB, Creager MA. Ascorbate restores endothelium-dependent vasodilation impaired by acute hyperglycemia in humans. Circulation (2001) 103(12):1618-23. doi:10.1161/01.CIR.103.12. 1618

80. Levine GN, Frei B, Koulouris SN, Gerhard MD, Keaney JF Jr, Vita JA. Ascorbic acid reverses endothelial vasomotor dysfunction in patients with coronary artery disease. Circulation (1996) 93(6):1107-13. doi:10.1161/01.CIR.93.6. 1107

81. Heller R, Unbehaun A, Schellenberg B, Mayer B, Werner-Felmayer G, Werner ER. L-ascorbic acid potentiates endothelial nitric oxide synthesis via a chemical stabilization of tetrahydrobiopterin. $J$ Biol Chem (2001) 276(1):40-7. doi:10.1074/jbc.M004392200

82. Huang A, Vita JA, Venema RC, Keaney JF Jr. Ascorbic acid enhances endothelial nitric-oxide synthase activity by increasing intracellular tetrahydrobiopterin. J Biol Chem (2000) 275(23):17399-406. doi:10.1074/jbc.M002248200

83. Wilkinson IB, Megson IL, MacCallum H, Sogo N, Cockcroft JR, Webb DJ. Oral vitamin $\mathrm{C}$ reduces arterial stiffness and platelet aggregation in humans. J Cardiovasc Pharmacol (1999) 34(5):690-3. doi:10.1097/ 00005344-199911000-00010

84. Sargeant LA, Khaw KT, Bingham S, Day NE, Luben RN, Oakes S, et al. Fruit and vegetable intake and population glycosylated haemoglobin levels: the EPIC-Norfolk study. Eur J Clin Nutr (2001) 55(5):342-8. doi:10.1038/sj.ejcn. 1601162

85. Myung SK, Ju W, Cho B, Oh SW, Park SM, Koo BK, et al. Efficacy of vitamin and antioxidant supplements in prevention of cardiovascular disease: systematic review and meta-analysis of randomised controlled trials. $B M J$ (2013) 346:f10. doi:10.1136/bmj.f10

86. Gale CR, Martyn CN, Winter PD, Cooper C. Vitamin C and risk of death from stroke and coronary heart disease in cohort of elderly people. BMJ (1995) 310(6994):1563-6. doi:10.1136/bmj.310.6994.1563

87. Kayden HJ, Traber MG. Absorption, lipoprotein transport, and regulation of plasma concentrations of vitamin E in humans. J Lipid Res (1993) 34(3):343-58.

88. Traber MG, Sokol RJ, Kohlschutter A, Yokota T, Muller DP, Dufour R, et al. Impaired discrimination between stereoisomers of alpha-tocopherol in patients with familial isolated vitamin E deficiency. J Lipid Res (1993) 34(2):201-10.

89. Schneider C. Chemistry and biology of vitamin E. Mol Nutr Food Res (2005) 49(1):7-30. doi:10.1002/mnfr.200400049

90. Traber MG, Sies H. Vitamin E in humans: demand and delivery. Annu Rev Nutr (1996) 16:321-47. doi:10.1146/annurev.nu.16.070196.001541

91. Islam KN, Devaraj S, Jialal I. alpha-Tocopherol enrichment of monocytes decreases agonist-induced adhesion to human endothelial cells. Circulation (1998) 98(21):2255-61. doi:10.1161/01.CIR.98.21.2255

92. Devaraj S, Li D, Jialal I. The effects of alpha tocopherol supplementation on monocyte function. Decreased lipid oxidation, interleukin 1 beta secretion, and monocyte adhesion to endothelium. J Clin Invest (1996) 98(3):756-63. doi:10.1172/JCI118848

93. Cominacini L, Garbin U, Pasini AF, Davoli A, Campagnola M, Contessi GB, et al. Antioxidants inhibit the expression of intercellular cell adhesion molecule-1 and vascular cell adhesion molecule- 1 induced by oxidized LDL on human umbilical vein endothelial cells. Free Radic Biol Med (1997) 22(1-2):117-27. doi:10.1016/S0891-5849(96)00271-7

94. Tasinato A, Boscoboinik D, Bartoli GM, Maroni P, Azzi A. d-alpha-tocopherol inhibition of vascular smooth muscle cell proliferation occurs at physiological concentrations, correlates with protein kinase $\mathrm{C}$ inhibition, and is independent of its antioxidant properties. Proc Natl Acad Sci U S A (1995) 92(26):12190-4. doi:10.1073/pnas.92.26.12190

95. Patrick L, Uzick M. Cardiovascular disease: C-reactive protein and the inflammatory disease paradigm: HMG-CoA reductase inhibitors, alpha-tocopherol, red yeast rice, and olive oil polyphenols. A review of the literature. Altern Med $\operatorname{Rev}(2001)$ 6(3):248-71.

96. Reaven PD, Khouw A, Beltz WF, Parthasarathy S, Witztum JL. Effect of dietary antioxidant combinations in humans. Protection of LDL by vitamin E but not by beta-carotene. Arterioscler Thromb (1993) 13(4):590-600. doi:10.1161/01. ATV.13.4.590 
97. Droge W. Free radicals in the physiological control of cell function. Physiol Rev (2002) 82(1):47-95. doi:10.1152/physrev.00018.2001

98. Sagach VF, Scrosati M, Fielding J, Rossoni G, Galli C, Visioli F. The watersoluble vitamin $\mathrm{E}$ analogue trolox protects against ischaemia/reperfusion damage in vitro and ex vivo. A comparison with vitamin E. Pharmacol Res (2002) 45(6):435-9. doi:10.1006/phrs.2002.0993

99. Otero P, Bonet B, Herrera E, Rabano A. Development of atherosclerosis in the diabetic $\mathrm{BALB} / \mathrm{c}$ mice. Prevention with vitamin $\mathrm{E}$ administration. Atherosclerosis (2005) 182(2):259-65. doi:10.1016/j.atherosclerosis.2005.02.024

100. Hasty AH, Gruen ML, Terry ES, Surmi BK, Atkinson RD, Gao L, et al. Effects of vitamin $\mathrm{E}$ on oxidative stress and atherosclerosis in an obese hyperlipidemic mouse model. J Nutr Biochem (2007) 18(2):127-33. doi:10.1016/j.jnutbio. 2006.03.012

101. Stephens NG, Parsons A, Schofield PM, Kelly F, Cheeseman K, Mitchinson MJ. Randomised controlled trial of vitamin $\mathrm{E}$ in patients with coronary disease: Cambridge heart antioxidant study (CHAOS). Lancet (1996) 347(9004):781-6. doi:10.1016/S0140-6736(96)90866-1

102. Lonn E, Yusuf S, Hoogwerf B, Pogue J, Yi Q, Zinman B, et al. Effects of vitamin $\mathrm{E}$ on cardiovascular and microvascular outcomes in high-risk patients with diabetes: results of the HOPE study and MICRO-HOPE substudy. Diabetes Care (2002) 25(11):1919-27. doi:10.2337/diacare.25.11.1919

103. Yusuf S, Dagenais G, Pogue J, Bosch J, Sleight P. Vitamin E supplementation and cardiovascular events in high-risk patients. The heart outcomes prevention evaluation study investigators. N Engl J Med (2000) 342(3):154-60. doi:10.1056/NEJM200001203420302

104. Jandak J, Steiner M, Richardson PD. Alpha-tocopherol, an effective inhibitor of platelet adhesion. Blood (1989) 73(1):141-9.

105. Norum KR, Blomhoff R. McCollum award lecture, 1992: vitamin A absorption, transport, cellular uptake, and storage. Am J Clin Nutr (1992) 56(4):735-44.

106. Di Mascio P, Kaiser S, Sies H. Lycopene as the most efficient biological carotenoid singlet oxygen quencher. Arch Biochem Biophys (1989) 274(2):532-8. doi:10.1016/0003-9861(89)90467-0

107. Mayne ST, Cartmel B, Silva F, Kim CS, Fallon BG, Briskin K, et al. Plasma lycopene concentrations in humans are determined by lycopene intake, plasma cholesterol concentrations and selected demographic factors. J Nutr (1999) 129(4):849-54

108. Korytko PJ, Rodvold KA, Crowell JA, Stacewicz-Sapuntzakis M, DiwadkarNavsariwala V, Bowen PE, et al. Pharmacokinetics and tissue distribution of orally administered lycopene in male dogs. J Nutr (2003) 133(9):2788-92.

109. Dewanto V, Wu X, Adom KK, Liu RH. Thermal processing enhances the nutritional value of tomatoes by increasing total antioxidant capacity. J Agric Food Chem (2002) 50:3010-4. doi:10.1021/jf0115589

110. Romanchik JE, Morel DW, Harrison EH. Distributions of carotenoids and alpha-tocopherol among lipoproteins do not change when human plasma is incubated in vitro. J Nutr (1995) 125(10):2610-7.

111. Dugas TR, Morel DW, Harrison EH. Impact of LDL carotenoid and alphatocopherol content on LDL oxidation by endothelial cells in culture. J Lipid Res (1998) 39(5):999-1007.

112. Fuhrman B, Elis A, Aviram M. Hypocholesterolemic effect of lycopene and beta-carotene is related to suppression of cholesterol synthesis and augmentation of LDL receptor activity in macrophages. Biochem Biophys Res Commun (1997) 233(3):658-62. doi:10.1006/bbrc. 1997.6520

113. Rao AV. Lycopene, tomatoes, and the prevention of coronary heart disease. Exp Biol Med (Maywood) (2002) 227(10):908-13.

114. Grosjean S, Devaux Y, Seguin C, Meistelman C, Zannad F, Mertes PM, et al. Retinoic acid attenuates inducible nitric oxide synthase (NOS2) activation in cultured rat cardiac myocytes and microvascular endothelial cells. J Mol Cell Cardiol (2001) 33(5):933-45. doi:10.1006/jmcc.2001.1356

115. Liu S, Lee IM, Ajani U, Cole SR, Buring JE, Manson JE. Intake of vegetables rich in carotenoids and risk of coronary heart disease in men: the physicians' health study. Int J Epidemiol (2001) 30(1):130-5. doi:10.1093/ije/30.1.130

116. Hozawa A, Jacobs DR Jr, Steffes MW, Gross MD, Steffen LM, Lee DH. Relationships of circulating carotenoid concentrations with several markers of inflammation, oxidative stress, and endothelial dysfunction: the coronary artery risk development in young adults (CARDIA)/young adult longitudinal trends in antioxidants (YALTA) study. Clin Chem (2007) 53(3):447-55. doi:10. 1373/clinchem.2006.074930

117. D’Odorico A, Martines D, Kiechl S, Egger G, Oberhollenzer F, Bonvicini P, et al. High plasma levels of alpha- and beta-carotene are associated with a lower risk of atherosclerosis: results from the Bruneck study. Atherosclerosis (2000) 153(1):231-9. doi:10.1016/S0021-9150(00)00403-2

118. Watzl B, Kulling SE, Moseneder J, Barth SW, Bub A. A 4-wk intervention with high intake of carotenoid-rich vegetables and fruit reduces plasma C-reactive protein in healthy, nonsmoking men. Am J Clin Nutr (2005) 82(5):1052-8.

119. Omenn GS, Goodman G, Thornquist M, Barnhart S, Balmes J, Cherniack M, et al. Chemoprevention of lung cancer: the beta-carotene and retinol efficacy trial (CARET) in high-risk smokers and asbestos-exposed workers. IARC Sci Publ (1996) 136:67-85.

120. Kohlmeier L, Kark JD, Gomez-Gracia E, Martin BC, Steck SE, Kardinaal AF, et al. Lycopene and myocardial infarction risk in the EURAMIC Study. Am J Epidemiol (1997) 146(8):618-26. doi:10.1093/oxfordjournals.aje.a009327

121. Karppi J, Laukkanen JA, Makikallio TH, Kurl S. Low serum lycopene and beta-carotene increase risk of acute myocardial infarction in men. Eur J Public Health (2012) 22(6):835-40. doi:10.1093/eurpub/ckr174

122. Muller L, Caris-Veyrat C, Lowe G, Bohm V. Lycopene and its antioxidant role in the prevention of cardiovascular diseases - a critical review. Crit Rev Food Sci Nutr (2015). doi:10.1080/10408398.2013.801827

123. O’Kennedy N, Crosbie L, van Lieshout M, Broom JI, Webb DJ, Duttaroy AK. Effects of antiplatelet components of tomato extract on platelet function in vitro and ex vivo: a time-course cannulation study in healthy humans. Am J Clin Nutr (2006) 84(3):570-9.

124. O'Kennedy N, Crosbie L, Whelan S, Luther V, Horgan G, Broom JI, et al. Effects of tomato extract on platelet function: a double-blinded crossover study in healthy humans. Am J Clin Nutr (2006) 84(3):561-9.

125. Gajendragadkar PR, Hubsch A, Maki-Petaja KM, Serg M, Wilkinson IB, Cheriyan J. Effects of oral lycopene supplementation on vascular function in patients with cardiovascular disease and healthy volunteers: a randomised controlled trial. PLoS One (2014) 9(6):e99070. doi:10.1371/journal.pone. 0099070

126. Dwyer JH, Navab M, Dwyer KM, Hassan K, Sun P, Shircore A, et al. Oxygenated carotenoid lutein and progression of early atherosclerosis: the Los Angeles atherosclerosis study. Circulation (2001) 103(24):2922-7. doi:10. 1161/01.CIR.103.24.2922

127. Sesso HD. Carotenoids and cardiovascular disease: what research gaps remain? Curr Opin Lipidol (2006) 17(1):11-6. doi:10.1097/01.mol. 0000203888.42514.27

128. Lidebjer C, Leanderson P, Ernerudh J, Jonasson L. Low plasma levels of oxygenated carotenoids in patients with coronary artery disease. Nutr Metab Cardiovasc Dis (2007) 17(6):448-56. doi:10.1016/j.numecd.2006.02.006

129. Austin RC, Lentz SR, Werstuck GH. Role of hyperhomocysteinemia in endothelial dysfunction and atherothrombotic disease. Cell Death Differ (2004) 11(Suppl 1):S56-64. doi:10.1038/sj.cdd.4401451

130. Chambers JC, Ueland PM, Obeid OA, Wrigley J, Refsum H, Kooner JS. Improved vascular endothelial function after oral B vitamins: an effect mediated through reduced concentrations of free plasma homocysteine. Circulation (2000) 102(20):2479-83. doi:10.1161/01.CIR.102.20.2479

131. Boger RH, Bode-Boger SM. Asymmetric dimethylarginine, derangements of the endothelial nitric oxide synthase pathway, and cardiovascular diseases. Semin Thromb Hemost (2000) 26(5):539-45. doi:10.1055/s-2000-13210

132. Jiang XH, Yang F, Tan HM, Liao D, Bryan RM, Randhawa JK, et al. Hyperhomocystinemia impairs endothelial function and eNOS activity via PKC activation. Arterioscler Thromb Vasc Biol (2005) 25(12):2515-21. doi:10.1161/ 01.ATV.0000189559.87328.e4

133. Garcia-Pinilla JM, Espinosa-Caliani S, Gomez-Doblas JJ, Jimenez-Navarro M, Gaitan MJ, Ortega-Jimenez MV, et al. Influence of high homocysteine and low folate plasmatic levels in medium-term prognosis after acute coronary syndromes. Int J Cardiol (2007) 118(2):220-6. doi:10.1016/j.ijcard.2006.06.053

134. Joshi R, Adhikari S, Patro BS, Chattopadhyay S, Mukherjee T. Free radical scavenging behavior of folic acid: evidence for possible antioxidant activity. Free Radic Biol Med (2001) 30(12):1390-9. doi:10.1016/S0891-5849(01) 00543-3

135. Carnicer R, Navarro MA, Arbones-Mainar JM, Acin S, Guzman MA, Surra JC, et al. Folic acid supplementation delays atherosclerotic lesion development in apoE-deficient mice. Life Sci (2007) 80(7):638-43. doi:10.1016/j.lfs. 2006.10.014

136. Endo N, Nishiyama K, Otsuka A, Kanouchi H, Taga M, Oka T. Antioxidant activity of vitamin B6 delays homocysteine-induced atheroscerosis in rats. $\mathrm{Br}$ J Nutr (2006) 95(6):1088-93. doi:10.1079/BJN20061764 
137. Gao L, Siu K, Chalupsky K, Nguyen A, Chen P, Weintraub NL, et al. Role of uncoupled endothelial nitric oxide synthase in abdominal aortic aneurysm formation: treatment with folic acid. Hypertension (2012) 59(1):158-66. doi:10.1161/HYPERTENSIONAHA.111.181644

138. Robinson K, Arheart K, Refsum H, Brattstrom L, Boers G, Ueland P, et al. Low circulating folate and vitamin B6 concentrations: risk factors for stroke, peripheral vascular disease, and coronary artery disease. European COMAC Group. Circulation (1998) 97(5):437-43. doi:10.1161/01.CIR.97.5.437

139. Naurath HJ, Joosten E, Riezler R, Stabler SP, Allen RH, Lindenbaum J. Effects of vitamin-B12, folate, and vitamin-B6 supplements in elderly people with normal serum vitamin concentrations. Lancet (1995) 346(8967):85-9. doi:10. 1016/S0140-6736(95)92113-3

140. den Heijer M, Brouwer IA, Bos GMJ, Blom HJ, van der Put NMJ, Spaans AP, et al. Vitamin supplementation reduces blood homocysteine levels a controlled trial in patients with venous thrombosis and healthy volunteers. Arterioscler Thromb Vasc Biol (1998) 18(3):356-61. doi:10.1161/01.ATV. 18.3.356

141. Till U, Rohl P, Jentsch A, Till H, Muller A, Bellstedt K, et al. Decrease of carotid intima-media thickness in patients at risk to cerebral ischemia after supplementation with folic acid, vitamins B6 and B12. Atherosclerosis (2005) 181(1):131-5. doi:10.1016/j.atherosclerosis.2004.12.043

142. Antoniades C, Shirodaria C, Crabtree M, Ratnatunga C, Pillai R, Neubauer $S$, et al. Low- and high- dose treatment with folic acid, equally improve endothelial function and decrease superoxide production in human vessels via tetrahydrobiopterin-mediated eNOS coupling. Eur Heart J (2007) 28:741.

143. Toole JF, Malinow MR, Chambless LE, Spence JD, Pettigrew LC, Howard VJ, et al. Lowering homocysteine in patients with ischemic stroke to prevent recurrent stroke, myocardial infarction, and death - the vitamin intervention for stroke prevention (VISP) randomized controlled trial. JAMA (2004) 291(5):565-75. doi:10.1001/jama.291.5.565

144. Debreceni B, Debreceni L. Why do homocysteine-lowering B vitamin and antioxidant $\mathrm{E}$ vitamin supplementations appear to be ineffective in the prevention of cardiovascular diseases? Cardiovasc Ther (2012) 30(4):227-33. doi:10. $1111 /$ j.1755-5922.2011.00266.x

145. Marti-Carvajal AJ, Sola I, Lathyris D, Salanti G. Homocysteine lowering interventions for preventing cardiovascular events. Cochrane Database Syst Rev (2009) 4:CD006612. doi:10.1002/14651858.CD006612.pub2

146. Halliwell B. Dietary polyphenols: good, bad, or indifferent for your health? Cardiovasc Res (2007) 73(2):341-7. doi:10.1016/j.cardiores.2006.10.004

147. Manach C, Scalbert A, Morand C, Remesy C, Jimenez L. Polyphenols: food sources and bioavailability. Am J Clin Nutr (2004) 79(5):727-47.

148. Watson RR, Preedy VR, Zibadi S. Polyphenols in Health and Disease. London: Academic Press (2014).

149. Stoclet JC, Chataigneau T, Ndiaye M, Oak MH, El Bedoui J, Chataigneau M, et al. Vascular protection by dietary polyphenols. Eur J Pharmacol (2004) 500(1-3):299-313. doi:10.1016/j.ejphar.2004.07.034

150. Quideau S, Deffieux D, Douat-Casassus C, Pouysegu L. Plant polyphenols: chemical properties, biological activities, and synthesis. Angew Chem Int Ed Engl (2011) 50(3):586-621. doi:10.1002/anie.201000044

151. Rodrigo R, Miranda A, Vergara L. Modulation of endogenous antioxidant system by wine polyphenols in human disease. Clin Chim Acta (2011) 412(5-6):410-24. doi:10.1016/j.cca.2010.11.034

152. Galleano M, Verstraeten SV, Oteiza PI, Fraga CG. Antioxidant actions of flavonoids: thermodynamic and kinetic analysis. Arch Biochem Biophys (2010) 501(1):23-30. doi:10.1016/j.abb.2010.04.005

153. Estevez L, Mosquera RA. Molecular structure and antioxidant properties of delphinidin. J Phys Chem A (2008) 112(42):10614-23. doi:10.1021/jp8043237

154. Prochazkova D, Bousova I, Wilhelmova N. Antioxidant and prooxidant properties of flavonoids. Fitoterapia (2011) 82(4):513-23. doi:10.1016/j.fitote.2011. 01.018

155. Finley JW, Kong AN, Hintze KJ, Jeffery EH, Ji LL, Lei XG. Antioxidants in foods: state of the science important to the food industry. J Agric Food Chem (2011) 59(13):6837-46. doi:10.1021/jf2013875

156. Babich H, Schuck AG, Weisburg JH, Zuckerbraun HL. Research strategies in the study of the pro-oxidant nature of polyphenol nutraceuticals. $J$ Toxicol (2011) 2011:467305. doi:10.1155/2011/467305

157. Halliwell B. Are polyphenols antioxidants or pro-oxidants? What do we learn from cell culture and in vivo studies? Arch Biochem Biophys (2008) 476(2):107-12. doi:10.1016/j.abb.2008.01.028
158. Gil-Longo J, Gonzalez-Vazquez C. Vascular pro-oxidant effects secondary to the autoxidation of gallic acid in rat aorta. J Nutr Biochem (2010) 21(4):304-9. doi:10.1016/j.jnutbio.2009.01.003

159. Middleton E Jr, Kandaswami C, Theoharides TC. The effects of plant flavonoids on mammalian cells: implications for inflammation, heart disease, and cancer. Pharmacol Rev (2000) 52(4):673-751.

160. Nicholson SK, Tucker GA, Brameld JM. Physiological concentrations of dietary polyphenols regulate vascular endothelial cell expression of genes important in cardiovascular health. Br J Nutr (2010) 103(10):1398-403. doi:10. 1017/S0007114509993485

161. Vari R, D’Archivio M, Filesi C, Carotenuto S, Scazzocchio B, Santangelo C, et al. Protocatechuic acid induces antioxidant/detoxifying enzyme expression through JNK-mediated Nrf2 activation in murine macrophages. J Nutr Biochem (2011) 22(5):409-17. doi:10.1016/j.jnutbio.2010.03.008

162. Wallace TC. Anthocyanins in cardiovascular disease. Adv Nutr (2011) 2(1):1-7. doi:10.3945/an.110.000042

163. Gresele P, Cerletti C, Guglielmini G, Pignatelli P, de Gaetano G, Violi F. Effects of resveratrol and other wine polyphenols on vascular function: an update. J Nutr Biochem (2011) 22(3):201-11. doi:10.1016/j.jnutbio.2010.07.004

164. Wang S, Melnyk JP, Tsao R, Marcone MF. How natural dietary antioxidants in fruits, vegetables and legumes promote vascular health. Food Res Intern (2011) 44(1):14-22. doi:10.1016/j.foodres.2010.09.028

165. Visioli F, Bernardini E. Extra virgin olive oil's polyphenols: biological activities. Curr Pharm Des (2011) 17(8):786-804. doi:10.2174/138161211795428885

166. Scalbert A, Johnson IT, Saltmarsh M. Polyphenols: antioxidants and beyond. Am J Clin Nutr (2005) 81(1 Suppl):215S-7S.

167. Kruger MJ, Davies N, Myburgh KH, Lecour S. Proanthocyanidins, anthocyanins and cardiovascular diseases. Food Res International (2014) 59:41-52. doi:10.1016/j.foodres.2014.01.046

168. Li J, Ichikawa T, Janicki JS. Cu8i T. Targeting the Nrf2 pathway against cardiovascular disease. Expert Opin Ther Targets (2009) 13(7):787-94. doi:10. $1517 / 14728220903025762$

169. Barbagallo I, Galvano F, Frigiola A, Cappello F, Riccioni G, Murabito P, et al. Potential therapeutic effects of natural heme oxygenase-1 inducers in cardiovascular diseases. Antioxid Redox Signal (2013) 18(5):507-21. doi:10. 1089/ars.2011.4360

170. Fraga CG, Galleano M, Verstraeten SV, Oteiza PI. Basic biochemical mechanisms behind the health benefits of polyphenols. Mol Aspects Med (2010) 31(6):435-45. doi:10.1016/j.mam.2010.09.006

171. Auger C, Kim JH, Trinh S, Chataigneau T, Popken AM, Schini-Kerth VB. Fruit juice-induced endothelium-dependent relaxations in isolated porcine coronary arteries: evaluation of different fruit juices and purees and optimization of a red fruit juice blend. Food Funct (2011) 2(5):245-50. doi:10.1039/ clfol0040h

172. Han XZ, Shen T, Lou HX. Dietary polyphenols and their biological significance. Int J Mol Sci (2007) 8(9):950-88. doi:10.3390/i8090950

173. Wiczkowski W, Romaszko E, Piskula MK. Bioavailability of cyanidin glycosides from natural chokeberry (Aronia melanocarpa) juice with dietaryrelevant dose of anthocyanins in humans. J Agric Food Chem (2010) 58(23):12130-6. doi:10.1021/jf102979z

174. McDougall GJ, Fyffe S, Dobson P, Stewart D. Anthocyanins from red wine their stability under simulated gastrointestinal digestion. Phytochemistry (2005) 66(21):2540-8. doi:10.1016/j.phytochem.2005.09.003

175. McDougall GJ, Dobson P, Smith P, Blake A, Stewart D. Assessing potential bioavailability of raspberry anthocyanins using an in vitro digestion system. J Agric Food Chem (2005) 53(15):5896-904. doi:10.1021/jf050131p

176. Yang M, Koo SI, Song WO, Chun OK. Food matrix affecting anthocyanin bioavailability: review. Curr Med Chem (2011) 18(2):291-300. doi:10.2174/ 092986711794088380

177. Scalbert A, Williamson G. Dietary intake and bioavailability of polyphenols. J Nutr (2000) 130(8S Suppl):2073S-85S.

178. Yang HL, Chen SC, Lin KY, Wang MT, Chen YC, Huang HC, et al. Antioxidant activities of aqueous leaf extracts of Toona sinensis on free radical-induced endothelial cell damage. JEthnopharmacol (2011) 137(1):669-80. doi:10.1016/ j.jep.2011.06.017

179. Stoner GD, Sardo C, Apseloff G, Mullet D, Wargo W, Pound V, et al. Pharmacokinetics of anthocyanins and ellagic acid in healthy volunteers fed freeze-dried black raspberries daily for 7 days. J Clin Pharmacol (2005) 45(10):1153-64. doi:10.1177/0091270005279636 
180. Faria A, Fernandes I, Norberto S, Mateus N, Calhau C. Interplay between anthocyanins and gut microbiota. J Agric Food Chem (2014) 62(29):6898-902. doi:10.1021/jf501808a

181. Banini AE, Boyd LC, Allen JC, Allen HG, Sauls DL. Muscadine grape products intake, diet and blood constituents of non-diabetic and type 2 diabetic subjects. Nutrition (2006) 22(11-12):1137-45. doi:10.1016/j.nut.2006.08.012

182. Khanizadeh S, Tsao R, Rekika D, Yang R, DeEll J. Phenolic composition and antioxidant activity of selected apple genotypes. J Food Agric Environ (2007) 5(1):61-6.

183. Chiou A, Salta FN, Kalogeropoulos N, Mylona A, Ntalla I, Andrikopoulos NK. Retention and distribution of polyphenols after pan-frying of French fries in oil enriched with olive leaf extract. J Food Sci (2007) 72(8):S574-84. doi:10.1111/j.1750-3841.2007.00493.x

184. Haenen GR, Paquay JB, Korthouwer RE, Bast A. Peroxynitrite scavenging by flavonoids. Biochem Biophys Res Commun (1997) 236(3):591-3. doi:10.1006/ bbrc.1997.7016

185. Hogg N, Darleyusmar V, Graham A, Moncada S, Kalyanaraman B. The modification of low-density-lipoprotein ( $\mathrm{Ldl}$ ) by peroxynitrite and systems generating nitric-oxide (No) and superoxide. Free Radic Biol Med (1993) 15(5):495. doi:10.1016/0891-5849(93)90277-2

186. Yamakoshi J, Kataoka S, Koga T, Ariga T. Proanthocyanidin-rich extract from grape seeds attenuates the development of aortic atherosclerosis in cholesterolfed rabbits. Atherosclerosis (1999) 142(1):139-49. doi:10.1016/S0021-9150(98) 00230-5

187. Kaplan M, Hayek T, Raz A, Coleman R, Dornfeld L, Vaya J, et al. Pomegranate juice supplementation to atherosclerotic mice reduces macrophage lipid peroxidation, cellular cholesterol accumulation and development of atherosclerosis. J Nutr (2001) 131(8):2082-9.

188. Andriambeloson E, Magnier C, Haan-Archipoff G, Lobstein A, Anton R, Beretz A, et al. Natural dietary polyphenolic compounds cause endotheliumdependent vasorelaxation in rat thoracic aorta. J Nutr (1998) 128(12): 2324-33.

189. Wallerath T, Li H, Godtel-Ambrust U, Schwarz PM, Forstermann U. A blend of polyphenolic compounds explains the stimulatory effect of red wine on human endothelial NO synthase. Nitric Oxide (2005) 12(2):97-104. doi:10. 1016/j.niox.2004.12.004

190. de Nigris F, Williams-Ignarro S, Lerman LO, Crimi E, Botti C, Mansueto G, et al. Beneficial effects of pomegranate juice on oxidation-sensitive genes and endothelial nitric oxide synthase activity at sites of perturbed shear stress. Proc Natl Acad Sci U S A (2005) 102(13):4896-901. doi:10.1073/pnas.0500998102

191. Stein JH, Keevil JG, Wiebe DA, Aeschlimann S, Folts JD. Purple grape juice improves endothelial function and reduces the susceptibility of LDL cholesterol to oxidation in patients with coronary artery disease. Circulation (1999) 100(10):1050-5. doi:10.1161/01.CIR.100.10.1050

192. Polagruto JA, Wang-Polagruto JF, Braun MM, Lee L, Kwik-Uribe C, Keen CL. Cocoa flavanol-enriched snack bars containing phytosterols effectively lower total and low-density lipoprotein cholesterol levels. J Am Diet Assoc (2006) 106(11):1804-13. doi:10.1016/j.jada.2006.08.012

193. Carluccio MA, Siculella L, Ancora MA, Massaro M, Scoditti E, Storelli C, et al. Olive oil and red wine antioxidant polyphenols inhibit endothelial activation: antiatherogenic properties of Mediterranean diet phytochemicals. Arterioscler Thromb Vasc Biol (2003) 23(4):622-9. doi:10.1161/01.ATV. 0000062884.69432.A0

194. de la Lastra CA, Villegas I. Resveratrol as an antioxidant and pro-oxidant agent: mechanisms and clinical implications. Biochem Soc Trans (2007) 35(Pt 5):1156-60. doi:10.1042/BST0351156

195. de la Lastra CA, Villegas I. Resveratrol as an anti-inflammatory and antiaging agent: mechanisms and clinical implications. Mol Nutr Food Res (2005) 49(5):405-30. doi:10.1002/mnfr.200500022

196. Karatzi K, Papamichael C, Karatzis E, Papaioannou TG, Voidonikola PT, Lekakis J, et al. Acute smoking induces endothelial dysfunction in healthy smokers. Is this reversible by red wine's antioxidant constituents? J Am Coll Nutr (2007) 26(1):10-5. doi:10.1080/07315724.2007.10719580

197. Martin S, Giannone G, Andriantsitohaina R, Martinez MC. Delphinidin, an active compound of red wine, inhibits endothelial cell apoptosis via nitric oxide pathway and regulation of calcium homeostasis. Br J Pharmacol (2003) 139(6):1095-102. doi:10.1038/sj.bjp.0705347

198. Rechner AR, Kroner C. Anthocyanins and colonic metabolites of dietary polyphenols inhibit platelet function. Thromb Res (2005) 116(4):327-34. doi:10.1016/j.thromres.2005.01.002
199. Freedman JE, Parker C III, Li L, Perlman JA, Frei B, Ivanov V, et al. Select flavonoids and whole juice from purple grapes inhibit platelet function and enhance nitric oxide release. Circulation (2001) 103(23):2792-8. doi:10.1161/ 01.CIR.103.23.2792

200. Demrow HS, Slane PR, Folts JD. Administration of wine and grape juice inhibits in vivo platelet activity and thrombosis in stenosed canine coronary arteries. Circulation (1995) 91(4):1182-8. doi:10.1161/01.CIR.91.4. 1182

201. Duarte J, Galisteo M, Ocete MA, Perez-Vizcaino F, Zarzuelo A, Tamargo J. Effects of chronic quercetin treatment on hepatic oxidative status of spontaneously hypertensive rats. Mol Cell Biochem (2001) 221(1-2):155-60. doi:10. 1023/A:1010956928584

202. Duarte J, Perez-Palencia R, Vargas F, Ocete MA, Perez-Vizcaino F, Zarzuelo A, et al. Antihypertensive effects of the flavonoid quercetin in spontaneously hypertensive rats. Br J Pharmacol (2001) 133(1):117-24. doi:10.1038/sj.bjp. 0704064

203. Han JJ, Hao J, Kim CH, Hong JS, Ahn HY, Lee YS. Quercetin prevents cardiac hypertrophy induced by pressure overload in rats. J Vet Med Sci (2009) 71(6):737-43. doi:10.1292/jvms.71.737

204. Jalili T, Carlstrom J, Kim S, Freeman D, Jin H, Wu TC, et al. Quercetinsupplemented diets lower blood pressure and attenuate cardiac hypertrophy in rats with aortic constriction. J Cardiovasc Pharmacol (2006) 47(4):531-41. doi:10.1097/01.fjc.0000211746.78454.50

205. Pereira Braga C, Momentti AC, Barbosa Peixoto F, de Fatima Ferreira Baptista $\mathrm{R}$, dos Santos FA, Fava FH, et al. Influence of treatment with quercetin on lipid parameters and oxidative stress of pregnant diabetic rats. Can J Physiol Pharmacol (2013) 91(2):171-7. doi:10.1139/cjpp-2012-0173

206. Heeba GH, Mahmoud ME, Hanafy AA. Anti-inflammatory potential of curcumin and quercetin in rats: role of oxidative stress, heme oxygenase1 and TNF-alpha. Toxicol Ind Health (2014) 30(6):551-60. doi:10.1177/ 0748233712462444

207. Choi EJ, Kim T, Kim GH. Quercetin acts as an antioxidant and downregulates CYP1A1 and CYP1B1 against DMBA-induced oxidative stress in mice. Oncol Rep (2012) 28(1):291-6. doi:10.3892/or.2012.1753

208. Luangaram S, Kukongviriyapan U, Pakdeechote P, Kukongviriyapan V, Pannangpetch P. Protective effects of quercetin against phenylhydrazine-induced vascular dysfunction and oxidative stress in rats. Food Chem Toxicol (2007) 45(3):448-55. doi:10.1016/j.fct.2006.09.008

209. Hertog MG, Feskens EJ, Hollman PC, Katan MB, Kromhout D. Dietary antioxidant flavonoids and risk of coronary heart disease: the Zutphen elderly study. Lancet (1993) 342(8878):1007-11. doi:10.1016/0140-6736(93) 92876-U

210. Hertog MG, Feskens EJ, Kromhout D. Antioxidant flavonols and coronary heart disease risk. Lancet (1997) 349(9053):699. doi:10.1016/S0140-6736(05) 60135-3

211. Geleijnse JM, Launer LJ, Van der Kuip DA, Hofman A, Witteman JC. Inverse association of tea and flavonoid intakes with incident myocardial infarction: the Rotterdam study. Am J Clin Nutr (2002) 75(5):880-6.

212. Hooper L, Kroon PA, Rimm EB, Cohn JS, Harvey I, Le Cornu KA, et al. Flavonoids, flavonoid-rich foods, and cardiovascular risk: a meta-analysis of randomized controlled trials. Am J Clin Nutr (2008) 88(1):38-50.

213. Egert S, Bosy-Westphal A, Seiberl J, Kurbitz C, Settler U, Plachta-Danielzik $S$, et al. Quercetin reduces systolic blood pressure and plasma oxidised low-density lipoprotein concentrations in overweight subjects with a high-cardiovascular disease risk phenotype: a double-blinded, placebocontrolled cross-over study. Br J Nutr (2009) 102(7):1065-74. doi:10.1017/ S0007114509359127

214. Mursu J, Nurmi T, Tuomainen TP, Ruusunen A, Salonen JT, Voutilainen S The intake of flavonoids and carotid atherosclerosis: the Kuopio ischaemic heart disease risk factor study. Br J Nutr (2007) 98(4):814-8. doi:10.1017/ S0007114507744410

215. Djousse L, Hopkins PN, Arnett DK, Pankow JS, Borecki I, North KE, et al. Chocolate consumption is inversely associated with calcified atherosclerotic plaque in the coronary arteries: the NHLBI family heart study. Clin Nutr (2011) 30(1):38-43. doi:10.1016/j.clnu.2010.06.011

216. Curtis PJ, Potter J, Kroon PA, Wilson P, Dhatariya K, Sampson M, et al. Vascular function and atherosclerosis progression after $1 \mathrm{y}$ of flavonoid intake in statin-treated postmenopausal women with type 2 diabetes: a double-blind randomized controlled trial. Am J Clin Nutr (2013) 97(5):936-42. doi:10.3945/ ajcn.112.043745 
217. Gronbaek M, Deis A, Sorensen TI, Becker U, Schnohr P, Jensen G. Mortality associated with moderate intakes of wine, beer, or spirits. BMJ (1995) 310(6988):1165-9. doi:10.1136/bmj.310.6988.1165

218. Semba RD, Ferrucci L, Bartali B, Urpi-Sarda M, Zamora-Ros R, Sun K, et al. Resveratrol levels and all-cause mortality in older community-dwelling adults. JAMA Intern Med (2014) 174(7):1077-84. doi:10.1001/jamainternmed.2014. 1582

219. Schrieks IC, van den Berg R, Sierksma A, Beulens JW, Vaes WH, Hendriks HF. Effect of red wine consumption on biomarkers of oxidative stress. Alcohol Alcohol (2013) 48(2):153-9. doi:10.1093/alcalc/ags086

220. Tozzi Ciancarelli MG, Di Massimo C, De Amicis D, Ciancarelli I, Carolei A. Moderate consumption of red wine and human platelet responsiveness. Thromb Res (2011) 128(2):124-9. doi:10.1016/j.thromres.2011.03.015

221. Droste DW, Iliescu C, Vaillant M, Gantenbein M, De Bremaeker N, Lieunard $\mathrm{C}$, et al. A daily glass of red wine associated with lifestyle changes independently improves blood lipids in patients with carotid arteriosclerosis: results from a randomized controlled trial. Nutr J (2013) 12(1):147. doi:10.1186/ 1475-2891-12-147

222. Chiva-Blanch G, Urpi-Sarda M, Ros E, Valderas-Martinez P, Casas R, Arranz $\mathrm{S}$, et al. Effects of red wine polyphenols and alcohol on glucose metabolism and the lipid profile: a randomized clinical trial. Clin Nutr (2013) 32(2):200-6. doi:10.1016/j.clnu.2012.08.022

223. Chiva-Blanch G, Urpi-Sarda M, Ros E, Arranz S, Valderas-Martinez P, Casas $\mathrm{R}$, et al. Dealcoholized red wine decreases systolic and diastolic blood pressure and increases plasma nitric oxide: short communication. Circ Res (2012) 111(8):1065-8. doi:10.1161/CIRCRESAHA.112.275636

224. Di Renzo L, Carraro A, Valente R, Iacopino L, Colica C, De Lorenzo A. Intake of red wine in different meals modulates oxidized LDL level, oxidative and inflammatory gene expression in healthy people: a randomized crossover trial. Oxid Med Cell Longev (2014) 2014:681318. doi:10.1155/2014/681318

225. Fairweather-Tait SJ, Bao Y, Broadley MR, Collings R, Ford D, Hesketh JE, et al. Selenium in human health and disease. Antioxid Redox Signal (2011) 14(7):1337-83. doi:10.1089/ars.2010.3275

226. Flores-Mateo G, Navas-Acien A, Pastor-Barriuso R, Guallar E. Selenium and coronary heart disease: a meta-analysis. Am J Clin Nutr (2006) 84(4): 762-73.

227. Rees K, Hartley L, Day C, Flowers N, Clarke A, Stranges S. Selenium supplementation for the primary prevention of cardiovascular disease (review). Cochrane Database Syst Rev (2013) 1:CD009671. doi:10.1002/14651858. CD009825.pub2

228. Beck MA, Esworthy RS, Ho YS, Chu FF. Glutathione peroxidase protects mice from viral-induced myocarditis. FASEB J (1998) 12(12):1143-9.

229. Lei C, Niu X, Wei J, Zhu J, Zhu Y. Interaction of glutathione peroxidase1 and selenium in endemic dilated cardiomyopathy. Clin Chim Acta (2009) 399(1-2):102-8. doi:10.1016/j.cca.2008.09.025

230. Ge K, Yang G. The epidemiology of selenium deficiency in the etiological study of endemic diseases in China. Am J Clin Nutr (1993) 57(2 Suppl):259S-63S.

231. Alfthan G, Xu GL, Tan WH, Aro A, Wu J, Yang YX, et al. Selenium supplementation of children in a selenium-deficient area in China - blood selenium levels and glutathione peroxidase activities. Biol Trace Elem Res (2000) 73(2):113-25. doi:10.1385/BTER:73:2:113

232. Rushworth GF, Megson IL. Existing and potential therapeutic uses for $\mathrm{N}$-acetylcysteine: the need for conversion to intracellular glutathione for antioxidant benefits. Pharmacol Ther (2014) 141(2):150-9. doi:10.1016/j. pharmthera.2013.09.006

233. Meister A, Anderson ME. Glutathione. Annu Rev Biochem (1983) 52:711-60. doi:10.1146/annurev.bi.52.070183.003431

234. Prescott LF, Ballantyne A, Park J, Adriaenssens P, Proudfoot AT. Treatment of paracetamol (acetaminophen) poisoning with $\mathrm{N}$-acetylcysteine. Lancet (1977) 2(8035):432-4. doi:10.1016/S0140-6736(77)90612-2

235. Martina V, Masha A, Gigliardi VR, Brocato L, Manzato E, Berchio A, et al. Long-term $\mathrm{N}$-acetylcysteine and L-arginine administration reduces endothelial activation and systolic blood pressure in hypertensive patients with type 2 diabetes. Diabetes Care (2008) 31(5):940-4. doi:10.2337/dc07-2251

236. Treweeke AT, Winterburn TJ, Mackenzie I, Barrett F, Barr C, Rushworth GF, et al. N-Acetylcysteine inhibits platelet-monocyte conjugation in patients with type 2 diabetes with depleted intraplatelet glutathione: a randomised controlled trial. Diabetologia (2012) 55(11):2920-8. doi:10.1007/ s00125-012-2685-z
237. Mazzanti L, Mutus B. Diabetes-induced alterations in platelet metabolism. Clin Biochem (1997) 30(7):509-15. doi:10.1016/S0009-9120(97)00094-5

238. Gibson KR, Winterburn TJ, Barrett F, Sharma S, MacRury SM, Megson IL. Therapeutic potential of $\mathrm{N}$-acetylcysteine as an antiplatelet agent in patients with type-2 diabetes. Cardiovasc Diabetol (2011) 10:43. doi:10.1186/ 1475-2840-10-43

239. Tamariz L, Harzand A, Palacio A, NVerna S, Jones J, Hare J. Uric acid as a predictor of all-cause mortality in heart failure: a meta-analysis. Congest Heart Fail (2011) 17:25-30. doi:10.1111/j.1751-7133.2011.00200.x

240. Naumova AV, Chacko VP, Ouwerkerk R, Stull L, Marban E, Weiss RG. Xanthine oxidase inhibitors improve energetics and function after infarction in failing mouse hearts. Am J Physiol Heart Circ Physiol (2006) 290:H837-43. doi:10.1152/ajpheart.00831.2005

241. Stull LB, Leppo MK, Szweda L, Gao WD, Marban E. Chronic treatment with allopurinol boosts survival and cardiac contractility in murine postischemic cardiomyopathy. Circ Res (2004) 95:1005-11. doi:10.1161/01.RES. 0000148635.73331.c5

242. Cappola TP, Kass DA, Nelson GS, Berger RD, Rosas GO, Kobeissi ZA, et al. Allopurinol improves myocardial efficiency in patients with idiopathic dilated cardiomyopathy. Circulation (2001) 104:2407-11. doi:10.1161/hc4501.098928

243. Hirsch GA, Bottomley PA, Gerstenblith G, Weiss RG. Allopurinol acutely increases adenosine triphosphate energy delivery in failing human hearts. J Am Coll Cardiol (2012) 59:802-8. doi:10.1016/j.jacc.2011.10.895

244. Givertz MM, Anstrom KJ, Redfield MM, Deswal A, Haddad H, Butler J, et al. Effect of xanthine oxidase inhibition in hyperuricemic heart failure patients: the xanthine oxidase inhibition for hyperuricemic heart failure patients (EXACT-HF) study. Circulation (2015) 131:1763-71. doi:10.1161/ CIRCULATIONAHA.114.014536

245. Hare JM, Mangal B, Brown J, Fisher CJ, Freudennberger R, Colucci WS, et al Impact of oxypurinol in patients with symptomatic heart failure: results of the OPT-CHF study. J Am Coll Cardiol (2008) 51:2301-9. doi:10.1016/j.jacc.2008. 01.068

246. Gavin AD, Struthers AD. Allopurinol reduces B-type natriuretic peptide concentrations and haemoglobin but does not alter exercise capacity in chronic heart failure. Heart (2005) 91:749-53. doi:10.1136/hrt.2004.040477

247. Greig D, Alcaino H, Castro PF, Garcia L, Verdejo HE, Nevarro M, et al Xanthine oxidase inhibitors and statins in chronic heart failure: effects on vascular and functional parameters. J Heart Lung Transplant (2011) 30:408-13. doi:10.1016/j.healun.2010.10.003

248. Nasr G, Maurice C. Allopurinol and global left myocardial function in heart failure patients. J Cardiovasc Dis Res (2010) 1:191-5. doi:10.4103/0975-3583. 74262

249. Cingolani HE, Plastino JA, Escudero EM, Mangal B, Brown J, Perez NG. The effect of xanthine oxidase inhibition upon ejection fraction in heart failure patients. La plat study. J Card Fail (2006) 12:491-8. doi:10.1016/j.cardfail.2006. 05.005

250. Tamariz L, Hare JM. Xanthine oxidase inhibitors in heart failure: where do we go from here? Circulation (2015) 131:1741-4. doi:10.1161/ CIRCULATIONAHA.115.016379

251. Okuda N, Miura K, Okayama A, Okamura T, Abbott RD, Nishi N, et al. Fruit and vegetable intake and mortality from cardiovascular disease in Japan: a 24-year follow-up of the NIPPON DATA80 Study. Eur J Clin Nutr (2015) 69(4):482-8. doi:10.1038/ejcn.2014.276

252. Li NY, Li K, Qi Z, Demonty I, Gordon M, Francis L, et al. Plant sterolenriched milk tea decreases blood cholesterol concentrations in Chinese adults: a randomised controlled trial. Br J Nutr (2007) 98(5):978-83. doi:10. 1017/S0007114507754302

Conflict of Interest Statement: The authors declare that the research was conducted in the absence of any commercial or financial relationships that could be construed as a potential conflict of interest.

Copyright (c) 2015 Goszcz, Deakin, Duthie, Stewart, Leslie and Megson. This is an open-access article distributed under the terms of the Creative Commons Attribution License (CC BY). The use, distribution or reproduction in other forums is permitted, provided the original author(s) or licensor are credited and that the original publication in this journal is cited, in accordance with accepted academic practice. No use, distribution or reproduction is permitted which does not comply with these terms. 